\title{
Diagnóstico de los manglares de Veracruz: distribución, vínculo con los recursos pesqueros y su problemática
}

\author{
Patricia Moreno Casasola ${ }^{1}$ \\ José Luis Rojas Galaviz ${ }^{1}$ \\ David Zárate Lomelí ${ }^{1,2}$ \\ Mario Arturo Ortiz Pérez ${ }^{3}$ \\ Ana Laura Lara Domínguez 1 \\ Teresa Saavedra Vázquez ${ }^{4}$
}

\begin{abstract}
RESUMEN
Se describe la superficie de manglar de la costa del estado de Veracruz a partir de 28 cartas de uso del suelo y vegetación del INEGI, escala 1:50 000, restituyendo fotografías aéreas escala 1:75 000 y 1:80 000. Se analiza la distribución del manglar, desde un punto de vista ecológico costero integral, con énfasis en los aspectos hidrológicos y geomorfológicos costeros, porque representan los principales factores de fuerza ambiental que determinan la magnitud y persistencia de los productores primarios costeros. Se analiza la relación que existe entre las áreas de manglar, la región hidrológica y la descarga fluvial identificadas en el litoral veracruzano con las capturas de los recursos pesqueros en la zona marina adyacente. Se obtuvieron valores de correlación positiva significativa entre el área de la cuenca hidrológica y la captura pesquera (0.9960 prob. 0.0040), lo que determina que las capturas pesqueras no dependen exclusivamente de un factor sino que son consecuencia ecológica de procesos costeros más complejos como lo implica el área de una cuenca hidrológica. El enfoque de la importancia ecológica y económica del manglar y las fuentes de contaminación e impacto ambiental que inciden sobre su distribución y abundancia, deberá regir las opciones de manejo y protección, utilizando la legislación y normatividad aplicables. Por ello, los límites del análisis rebasan el ámbito exclusivo de la localización específica de los bosques de manglar, y es necesario un enfoque integral de abordar su problemática para comprender mejor tanto los efectos como las causas que los determinan.
\end{abstract}

PALABRAS CLAVE:

Diagnóstico, impactos ambientales, manglares, recursos pesqueros, Veracruz.

\begin{abstract}
The mangrove area of the coast of the State of Veracruz is determined from 28 maps of land use and vegetation from the INEGI, (1:50 000), and the interpretation of aerial photographies of the land use (1:75 000 and 1:80 000). The distribution of the mangroves is analyzed with emphasis on the hydrological aspects and coastal geomorphology, because they represent the main environmental forcing functions that determine the magnitude and persistence of the coastal primary producers. The relationship among commercial capture of fishing resources and the mangrove areas, watershed area and fluvial discharge identified in the veracruzan coast is analyzed by regression. The watershed area presents significant positive correlation ( 0.9960 prob. 0.0040). This determines that the fishing captures do not depend exclusively of one factor rather they are the ecological consequence of more complex coastal processes. The pollution sources and environmental impacts due to urban growth determine the mangrove distribution and abundance in the Veracruz coastal zone. Therefore, it will be necessary to establish the management options of protection and conservation under the present legislation. The mangrove areas analysis surpasses the exclusive environmental location, and it is necessary an integral analysis of their problem to better understand the effects and the causes that determine them.
\end{abstract}

KEY WORDS:

Diagnostic, environmental impact, mangroves, fisheries, Veracruz. 


\section{INTRODUCCIÓN}

Para comprender la distribución y abundancia de los bosques de manglar en el estado de Veracruz, es indispensable conocer las relaciones bióticas y abióticas que se manifiestan en los sistemas costeros (ecosistema estuarino), con los adyacentes hacia el continente (ecosistema fluvial) y hacia el océano (ecosistema marino). Ello conduce a visualizar unidades de trabajo en el ámbito de cuenca y de región hidrológica, que permitan establecer claramente las interacciones con las superficies terrestres y los aportes de agua dulce y marina.

Las característica ecológicas más importantes que vinculan la secuencia ríoestuario-mar en clima tropical fueron integradas en un modelo conceptual para el sistema fluvio-lagunar Palizada del Este, en la región de la Laguna de Términos en Campeche, presentado por Vera et al. (1988). Para ello, emplearon la representación gráfica propuesta por Haines (1979), para las interacciones de los pantanos costeros en clima templado. El modelo generado hace evidente la complejidad de las relaciones bióticas y abióticas entre estos ambientes, así como la magnitud de los vínculos ecológicos entre las tierras bajas costeras y la zona marina adyacente. El modelo propone que la existencia de los productores primarios (humedales, manglar, macroalgas y pastos marinos) a lo largo de la secuencia río-estuario-mar, dependen en gran medida, de la intensidad de la dinámica abiótica-hidrológica que existe desde los ríos hasta el mar. Ésta involucra agua dulce, sedimentos terrígenos y nutrimentos inorgánicos, mientras que en el sentido inverso implica energía mareal e intrusiones salobres. La existencia de bosques de manglar más extensos y productivos localizados en los ecosistemas fluvio-lagunar-deltáico-estuarinos y bosques con menor desarrollo en los ecosistemas estuarinos-marinos, son efectos estructurales derivados de una dinámica fluvial-mareal.
Para explicar las variaciones en los tamaños y estructura de los manglares, Thom (1982) los clasifica en cinco tipos con base en un conjunto de características topográficas e hidrodinámicas dadas por la situación geomorfológica. Así mismo, Lugo y Snedaker (1974) desarrollaron una clasificación de los bosques de manglar basados en las características fisiográficas, presumiendo que estas reflejaban los grados de predominio de las funciones de fuerzas ambientales (sensu Twilley 1988 y 1995) tales como radiación solar, frecuencia de vientos, precipitación, descarga o influencia del río y la marea (a través de la turbidez causada por el material suspendido, el aporte de materia orgánica y nutrimentos, así como el contenido de sal).

El esquema original de estos autores, describía seis tipos fisiográficos, que posteriormente fueron simplificados por Cintrón et al. (1980). Estos autores, a partir del análisis de las características estructurales, proponen cuatro tipos: 1. Bosques ribereños, 2. Bosques de borde, 3. Bosques de cuenca y, 4. Bosques especiales. Cada uno de ellos se caracteriza por presentar una estructura particular, dominancia diferente de especies y condiciones ambientales distintas. La geomorfología asociada a cada tipo determina en gran medida el impacto del oleaje y el viento, la interacción con las mareas y el agua dulce y por tanto determina de manera importante la productividad del manglar (Twilley y Day, 1999; Yáñez y Lara, 1999).

Estas funciones de fuerza son dominantes en los manglares $y$ colectivamente representan la huella de energía de los mismos (Twilley, 1995; Medina, 1999). Odum (1967) fundamentó el concepto de huella energética para describir los factores que operan en un sistema e influyen en sus funciones. Por lo tanto, los manglares son ecosistemas altamente subsidiados por fuentes de energía externas al sistema. La interacción de las funciones de fuerza ambiental determinan el grado máximo de estructura 
que puede desarrollar una comunidad de manglar. Entre los componentes planteados, el recurso forestal es el responsable de la estructura de la comunidad y define gran parte de las interacciones con el componente biótico y abiótico.

Con lo que respecta a los manglares, estos son árboles halófitos facultativos y crecen prolíficamente a lo largo de costas sedimentarias bajas situadas en áreas deltáicas donde predomina sustrato limoarcilloso más que arena. Asimismo, la cobertura de los bosques de manglar es más extensa en áreas costeras asociada a grandes descargas de los ríos que proporcionan nutrientes y crean ambientes de baja salinidad (Cintrón y Schaeffer, 1992; Kjerfve et al., 1999). La existencia del manglar, conjuntamente con los demás productores primarios de los pantanos dulceacuícolas y salobres, así como de los ecosistemas estuarinos representan exportación de materia orgánica disuelta y particulada hacia el mar. Esta exportación es un factor que determina la permanencia en el tiempo y la magnitud de los recursos pesqueros marinos regionales. Por ello, tanto las características regionales de las pesquerías marinas como las del manglar, no dependen exclusivamente de un factor. En realidad son la consecuencia ecológica de procesos costeros mucho más complejos que han sido referidos como puentes ecológicos (Vera et al., 1988) y mecanismos de producción (Soberón et al., 1986), los cuales incluyen un número mayor de factores de fuerza ambiental.

\section{Problemática ambiental}

No obstante la importancia ecológica de los manglares, el proceso de conversión de áreas para el desarrollo de actividades productivas es cada vez más intenso y ha llevado al deterioro, así como a la pérdida definitiva de valiosos recursos naturales y de funciones ecológicas. Por ejemplo, en Ecuador, la conversión masiva de manglares para la camaronicultura (14\%-16\% de la superficie de manglar, a razón de 2618 ha/año) ha inducido entre otros efectos, la falta de postlarvas de camarón y pérdidas económicas (Lahmann et al., 1987; Olsen et al., 1989; Twilley, 1989; Twilley et al., 1999). En los Everglades en Florida, Estados Unidos, de los $10000 \mathrm{~km}^{2}$ de pantanos (incluyendo manglares), más del $65 \%$ han desaparecido por obras hidráulicas, desarrollo urbano y actividades agropecuarias, generando con ello serios problemas ambientales y pérdidas económicas (Hofstetter, 1988; Kushlan, 1988). En México no existen valoraciones precisas de la desaparición de humedales y pantanos de agua dulce. Flores et al. (1971) calcularon con base en fotografías aéreas y recorridos de campo que los manglares ocupaban 1420000 ha en el país. Blasco (1988 citado en Flores et al., 1992) calculó una extensión de 660000 ha, Loa (1994) de 488400 ha y Yáñez (1999) de 524600 ha. Sin embargo, estos valores sólo aparecen en los trabajos, sin especificar los cálculos y la metodología empleada para la estimación de cada uno.

En México, la SARH (1970 y 1991) indicó en el Inventario Forestal de Gran Visión de 1970 una superficie de $1.5 \times 10^{6}$ ha, pero en el Inventario Forestal de Gran Visión de 1991 señaló que sólo quedan en existencia un poco más de $500 \times 10^{3}$ ha reflejando una tasa de deforestación de $60 \%$ en 20 años (Yáñez et al., 1998 y 1999). Lo que sí es evidente, es que actividades como el establecimiento de granjas camaronícolas, sobre todo en el Pacífico de nuestro país, desarrollos turísticos (Ixtapa, Cancún), la expansión de los terrenos pecuarios y la tala clandestina han continuado disminuyendo considerablemente la superficie de manglares.

Las principales causas de la pérdida de manglares se deben en síntesis, a la aplicación de políticas económicas productivistas orientadas hacia la obtención de ganancias a corto plazo. Entre estas causas se puede señalar la explotación forestal irracional, la modificación de la hidrología por desviaciones de los cauces 
fluviales con fines agrícolas, la sustitución de áreas de manglar por obras de acuacultura o de infraestructura turística, entre otras. La falta de planes de manejo para estos tipos de vegetación y la limitada planificación y ordenamiento de actividades productivas y el desconocimiento o dificultad para determinar el valor ecológico y económico de los bienes, atributos y servicios que proporcionan estos ambientes son también causas importantes de su desaparición.

De aquí la necesidad de desarrollar un diagnóstico de los bosques de manglar en el estado de Veracruz. Este proporcionará la información para el planteamiento de estrategias de uso y manejo de estos ecosistemas, conducente a su uso sustentable y conservación. Estas estrategias deberán plantear el mantenimiento de las funciones de los manglares en la protección de la línea de costa, así como áreas de alta diversidad biológica y como áreas de crianza para numerosas especies de animales con importancia comercial.

\section{OBJETIVOS}

- Desarrollar una metodología comparativa para la determinación de las áreas de manglar en el estado de Veracruz empleando fotografías aéreas e imágenes de satélite tomadas en diferentes años.

- Determinar la distribución y abundancia del manglar en el estado de Veracruz desde un punto de vista ecológico costero integral, haciendo énfasis en los aspectos hidrológicos y geomorfológicos costeros que representan los principales factores de fuerza ambiental que determinan su magnitud y persistencia.

- Determinar la relación que existe entre las áreas de manglar y la producción pesquera, así como la relación que guarda con otros factores como es el tamaño de la cuenca y las descargas de agua dulce en el litoral veracruzano.
- Recopilar información de las principales fuentes de deterioro en los ecosistemas de manglar.

\section{ÁREA DE ESTUDIO}

Veracruz cuenta con un litoral de 745 kilómetros de longitud. Sus costas corresponden a una franja marginal afectada por las variaciones de la marea y limitada hacia el continente por los humedales adyacentes. El relieve consiste en su mayor parte de una llanura costera de ancho variable (entre $20 \mathrm{~km}$ y $150 \mathrm{~km}$ ), donde se reconocen corrientes fluviales y lagunas costeras de diversa magnitud. Los enlaces de transición entre el ambiente terrestre $y$ el marino son diversos e incluyen islas de barrera, sistemas lagunares-estuarinos, sistemas fluvio-lagunar-deltáico-estuarinos, sistemas fluvio-deltáicos, campos de dunas, marismas con halófitas, manglares, humedales dulceacuícolas y planicies costeras.

\section{METODOLOGÍA}

Para la determinación de las áreas de manglar se desarrolló la siguiente metodología.

\section{Evaluación de la cobertura de manglar}

1) A partir de 28 cartas de uso del suelo y vegetación del Instituto Nacional de Estadística, Geografía e Informática (INEGI), escala 1:50 000, se digitalizó la línea de costa del estado de Veracruz lo que constituye el mapa base para el vaciado de la información que se generaría posteriormente.

2) Se realizó la fotointerpretación del uso del suelo con base en a) fotografías aéreas escala $1: 75000$ y 1:80 000 de los años de 1975, 1976, y 1980; b) fotografía aérea escala 1:250 000 de 1993 y c) con imágenes de satélite utilizadas en el inventario nacional 
forestal de 2000, escala 1:125 000 (Palacios et al., 2000).

3) Las unidades obtenidas con la fotointerpretación fueron restituidas en el mapa base y digitalizadas por medio del sistema de información geográfica ILWIS.

4) Con base en lo anterior se midieron las áreas de las unidades resultantes y se elaboraron las gráficas respectivas.

Así mismo, se analizaron de manera integrada, las características geomorfológicas e hidrológicas más relevantes de la costa del estado de Veracruz, ya que éstas constituyen factores determinantes en la magnitud y presencia de los bosques de manglar.

\section{Evaluación de actividades económicas}

Los datos de superficie lagunar, de infraestructura petrolera, y de las capturas pesqueras del año 1993 para los municipios costeros del estado de Veracruz, fueron obtenidos de los documentos publicados por la Secretaría de Desarrollo Agropecuario, Forestal y Pesquero del estado de Veracruz, referidas a las estadísticas oficiales de la Secretaría de Pesca (SEDAP, 1997). Se hizo una revisión bibliográfica que permitió reunir los datos existentes acerca de la contaminación producida por aguas negras y por hidrocarburos en los ríos y lagunas de Veracruz (Botello y Toledo, 1996; Botello et al., 1996a y b; Silva y Botello, 1996; Toledo et al., 1989; Villanueva y Paez, 1996; Wong y Barrera, 1996).

\section{Vínculo de las actividades pesqueras y la cobertura de manglar}

Con el propósito de determinar la relación que existe entre la captura pesquera y las áreas de manglar, descarga fluvial total, y área de la cuenca hidrológica se determinaron los coeficientes de correlación de Pearson (Turner, 1977; Soberón y Yáñez, 1985; Childers et al., 1990). Este coeficiente calcula la intensidad de la relación lineal entre cada par de variables (SAS Institute, Inc. 1999).

\section{RESULTADOS}

Cobertura y descripción de los manglares de Veracruz y su importancia para la captura pesquera regional

\section{Descripción geomorfológica e hidroló- gica de la costa}

Por la influencia marina y los procesos costeros prevalecientes en el litoral, la zona costera de Veracruz se dividió en cinco regiones geomorfológicas:

Región Norte. Se localiza entre el Río Pánuco y el Río Tecolutla (Tabla 1). La línea de costa está formada por playas protegidas por islas de barrera con la presencia de lagunas y esteros orientados de manera paralela a la línea de costa. Las islas de barrera son una evidencia de la importancia que tiene la circulación de sedimentos de deriva litoral con dirección generalizada norte-sur. Incluye también costas acumulativas de playas arenosas con exposición abierta al mar.

Región Centro-Norte. Se localiza entre el Río Nautla y el Río Actopan (Tabla 1). Predominan las costas mixtas abrasivoacumulativas con tramos de costas con salientes rocosas alternados con embahiamientos amplios que dan lugar gradualmente a playas bajas abiertas al mar y en contacto con campos de dunas dispuestas a sotavento.

Región Centro. Localizada entre el Río Antigua y Lerdo de Tejada (Tabla 1). Predominan playas bajas con extensos campos de dunas que penetran varios kilómetros tierra adentro, y logran alturas de 90 m con escasas cubetas de deflación en la franja de dunas móviles activas. La descarga de los ríos es autóctona, por lo que no hay impacto o éste sólo tiene una 
Tabla 1. Superficie de manglar identificada para 28 Cartas INEGI de la costa de Veracruz a la escala 1:50 000 (en orden norte-sur)

\begin{tabular}{|c|c|c|c|c|}
\hline $\begin{array}{l}\text { REGIÓN. } \\
\text { GEOMOR- } \\
\text { FOLÓGICA }\end{array}$ & $\begin{array}{c}\text { CUENCA } \\
\text { HIDROLÓGICA } \\
\text { Y } \\
\text { DESCARGA }\end{array}$ & MUNICIPIO & $\begin{array}{l}\text { NOMBRE } \\
\text { DE LA } \\
\text { CARTA INEGI }\end{array}$ & RÍOS \\
\hline \multirow{12}{*}{$\begin{array}{l}\text { Región } \\
\text { Norte }\end{array}$} & $\begin{array}{c}\mathrm{RH} 26 \\
\text { Pánuco } \\
\text { Descarga } 14057 \\
\text { millones de metros } \\
\text { cúbicos }\end{array}$ & $\begin{array}{l}\text { Pueblo Viejo } \\
\text { Tampico Alto }\end{array}$ & Tampico Sur & $\begin{array}{c}\text { Pánuco, Tamesí, } \\
\text { Tamacuil, } \\
\text { Moctezuma }\end{array}$ \\
\hline & \multirow{15}{*}{$\begin{array}{c}\mathrm{RH} 27 \\
\text { Tuxpan-Nautla } \\
\text { Descarga } 14193 \\
\text { millones de metros } \\
\text { cúbicos }\end{array}$} & Tampico Alto & Llano de Bustos & \\
\hline & & Ozuluama & Barra Arenosa & \\
\hline & & No se registró & Ozuluama & \\
\hline & & Ozuluama-Tamalín & Cabo Rojo & \\
\hline & & Tamihua & Tamiahua & \\
\hline & & Tamiahua & Temapache & Tuxpan \\
\hline & & No se registró & Arrecife Tanhuijo & \\
\hline & & Tuxpan & Tuxpan & \\
\hline & & Tuxpan & Barra Norte & \\
\hline & & Cazones & Cazones & Cazones \\
\hline & & Papantla-Tecolutla & Papantla & Tecolutla \\
\hline \multirow{5}{*}{$\begin{array}{l}\text { Región } \\
\text { Centro } \\
\text { Norte }\end{array}$} & & Nautla & La Guadalupe & \multirow{2}{*}{ Nautla } \\
\hline & & Nautla & San Rafael & \\
\hline & & Vega de Alatorre & Vega de Alatorre & Colipa \\
\hline & & Alto Lucero & V. Emilio Carranza & \\
\hline & \multirow{10}{*}{$\begin{array}{c}\mathrm{RH} 28 \\
\text { Papaloapan } \\
\text { Descarga } 42884 \\
\text { millones de metros } \\
\text { cúbicos }\end{array}$} & Actopan & Actopan & Actopan \\
\hline \multirow{6}{*}{$\begin{array}{l}\text { Región } \\
\text { Centro }\end{array}$} & & No se registró & La Antigua & Antigua \\
\hline & & Veracruz-B. del Río & Veracruz & $\begin{array}{c}\text { Jamapa, Río } \\
\text { Atoyac }\end{array}$ \\
\hline & & No se registró & Antón Lizardo & Blanco \\
\hline & & Alvarado & Alvarado & \multirow{3}{*}{$\begin{array}{c}\text { Papaloapan, R.V. } \\
\text { nacional y Río } \\
\text { Tecomate }\end{array}$} \\
\hline & & Alvarado & Mixtequilla & \\
\hline & & Lerdo de Tejada & Lerdo de Tejada & \\
\hline \multirow{3}{*}{$\begin{array}{l}\text { Región } \\
\text { Centro Sur }\end{array}$} & & Angel & La Nueva Victoria & \\
\hline & & Soteapan & La Perla del Golfo & \\
\hline & & No se registró & San Juan Volador & \\
\hline \multirow{2}{*}{ Región Sur } & \multirow{2}{*}{$\begin{array}{c}\mathrm{RH} 29 \\
\text { Coatzacoalcos } \\
\text { Descarga } 32941 \\
\text { millones de metros } \\
\text { cúbicos }\end{array}$} & Coatzacoalcos & Coatzacoalcos & $\begin{array}{l}\text { Coatzacoalcos, } \\
\text { Río Uxpanapa }\end{array}$ \\
\hline & & Agua Dulce & Agua Dulce & Tonalá \\
\hline
\end{tabular}


Tabla 1. Superficie de manglar identificada para 28 Cartas INEGI de la costa de Veracruz a la escala 1:50 000 (en orden norte-sur, cont...)

\begin{tabular}{|c|c|c|c|c|}
\hline $\begin{array}{l}\text { REG. } \\
\text { GEOMOR- } \\
\text { FOLÓGICA }\end{array}$ & LAGUNA & $\begin{array}{l}\text { SUPERFICIE DE } \\
\text { MANGLAR } \\
\text { (ha) }\end{array}$ & $\begin{array}{l}\text { PORCENTAJE } \\
\text { DE LA SUPER- } \\
\text { FICIE TOTAL DE } \\
\text { MANGLAR }\end{array}$ & $\begin{array}{l}\text { CLAVE DE LA } \\
\text { CARTA INEGI }\end{array}$ \\
\hline \multirow{12}{*}{$\begin{array}{l}\text { Región } \\
\text { Norte }\end{array}$} & $\begin{array}{l}\text { Pueblo Viejo, Chairel, } \\
\text { Chijol, Tamos, Tortuga, Las } \\
\text { Pintas, Estero Vado, Paité, } \\
\text { Topila, entre otras }\end{array}$ & 661 & 1.51 & F14B84 \\
\hline & \multirow[t]{5}{*}{ Tamiahua } & 743 & 1.70 & F14D14 \\
\hline & & 525 & 1.20 & F14D15 \\
\hline & & 0 & 0.00 & F14D24 \\
\hline & & 5700 & 13.01 & F14D25 \\
\hline & & 8941 & 20.41 & F14D35 \\
\hline & \multirow{6}{*}{$\begin{array}{l}\text { Tampamachoco, San } \\
\text { Agustín, Grande }\end{array}$} & 960 & 2.19 & F14D45 \\
\hline & & 0 & 0.00 & F14D46 \\
\hline & & 731 & 1.67 & F14D55 \\
\hline & & 528 & 1.21 & F14D56 \\
\hline & & 723 & 1.65 & F14D66 \\
\hline & & 316 & 0.72 & F14D76 \\
\hline \multirow{5}{*}{$\begin{array}{l}\text { Región } \\
\text { Centro } \\
\text { Norte }\end{array}$} & & 1785 & 4.07 & F14D77 \\
\hline & & 288 & 0.66 & F14D87 \\
\hline & & 194 & 0.44 & F14D88 \\
\hline & & 110 & 0.25 & E14B18 \\
\hline & El Llano, La Mancha & 552 & 1.26 & E14B28 \\
\hline \multirow{6}{*}{$\begin{array}{l}\text { Región } \\
\text { Centro }\end{array}$} & & 0 & 0.00 & E14B39 \\
\hline & Mandinga & 460 & 1.05 & E14B49 \\
\hline & & 0 & 0.00 & $\mathrm{E} 15 \mathrm{~A} 41$ \\
\hline & Alvarado, Sontecomapan & 356 & 0.81 & E15A51 \\
\hline & & 14334 & 32.72 & $\mathrm{E} 15 \mathrm{~A} 61$ \\
\hline & & 144 & 0.33 & E15A62 \\
\hline \multirow{3}{*}{$\begin{array}{l}\text { Región } \\
\text { Centro Sur }\end{array}$} & & 502 & 1.15 & E15A63 \\
\hline & & 599 & 1.37 & E15A64 \\
\hline & & 0 & 0.00 & E15A74 \\
\hline \multirow{4}{*}{ Región Sur } & del Ostión & 1620 & 3.70 & E15A85 \\
\hline & & & & \\
\hline & & 3039 & 6.94 & E15A86 \\
\hline & Total & 43811 & 100.00 & \\
\hline
\end{tabular}


influencia local en el ambiente. La excepción es el complejo fluvio-lagunar deltáico-estuarino de Alvarado que puede ser considerado por sus condiciones, una región con características distintivas. Sin embargo, está incluida en esta región debido a que su litoral está bordeado por amplios y elevados campos de dunas.

Región Centro-Sur. Corresponde al borde litoral del complejo volcánico de los Tuxtlas (Tabla 1). Geomorfológicamente, la costa es rocosa con tramos de playas arenosas que indican el carácter abrasivo-acumulativo del modelado costero de origen volcánico. A nivel sublitoral hay cambios, puesto que la celda de deriva costera (norte-sur), que es evidente en la parte norte, se pierde por completo en esta región.

Región Sur. Comprende los humedales de la Laguna del Ostión, el Río Coat-zacoalcos junto con los esteros de La Alameda y Pajaritos hasta el Río Tonalá (Tabla 1). Se caracteriza por la presencia de playas con una franja de dunas activas, así como también la fuerte influencia de los Ríos Coatzacoalcos y Tonalá lo que ocasiona la existencia de importantes sistemas estuarinos. A nivel sublitoral, se distingue porque la corriente costera dominante de deriva es de este a oeste, la cual desaparece después de Boca de la Laguna del Ostión en la región de los Tuxtlas.

\section{Superficies de manglar}

Con base en los resultados obtenidos a partir de las unidades restituidas en las 28 Cartas de INEGI, la superficie total de manglar en Veracruz es de 43811 ha. La mayor extensión se identifica en la Carta "Mixtequilla" con 14334 ha, y corresponde al 30.27\% del total estatal. Esta superficie se localiza en el complejo lagunar de Alvarado y constituye la mayor superficie de manglar en el estado (Tabla 1, Fig. 1).

Las Cartas Cabo Rojo y Tamiahua registran valores entre 5000 y 10000 ha con un total de 14641 ha (Tabla 1, Fig. 1).
En las Cartas La Guadalupe, Coatzacoalcos y Agua Dulce se dan valores entre 1000 ha y 5000 ha (que en conjunto producen un total de $6444 \mathrm{ha}$ ).

Sin embargo, en la mayoría de las cartas analizadas (22), los valores de superficie de manglar fueron pequeños fluctuando entre 0 ha y 1000 ha. En cinco cartas no se registró manglar (Ozuluama, Arrecife Tanhuijo, La Antigua, Antón Lizardo, San Juan Volador). La cobertura de manglar en conjunto de estas cartas es de 8392 ha (Tabla 1, Fig. 1).

Los datos anteriores muestran que el tamaño de las superficies de manglar a lo largo del litoral de Veracruz es sumamente variable. Más de la tercera parte (34\%) de la cobertura de manglar en Veracruz está formada por áreas menores de 5000 ha (Fig. 2A). Las superficies entre 5000 ha y 10000 ha constituyen el $33 \%$ y el restante $33 \%$ está formado por las superficies entre 10000 ha y 15000 ha (Fig. 2A).

Por otro lado, con la restitución de las fotografías aéreas de 1993, se calculó una superficie de manglar de 46074 ha, mientras que con las imágenes de satélite que fueron utilizadas en el Inventario Forestal Nacional 2000 se obtuvo un área de 42125.1 ha (Tabla 2). Existen diferencias en las superficies de manglar determinadas por fotografías aéreas entre 1975 a 1980 y las estimadas en 1993. Se observa un incremento en 2554.92 ha. Mientras que para la superficie determinada para el 2000 , se registra una disminución de 1685.90 ha.

\section{Cuencas hidrológicas y distribución del manglar}

Por sus características hidrológicas y en función de los límites de cuencas hidrológicas establecidos por la Comisión Nacional del Agua, en la costa veracruzana se delimitan cuatro regiones de norte a sur, que cubren una superficie total de 72815 ha: Región H-26 Pánuco, 27 Nautla-Tuxpan, 28 Papaloapan y 29 Coatzacoalcos (Tabla 1). 


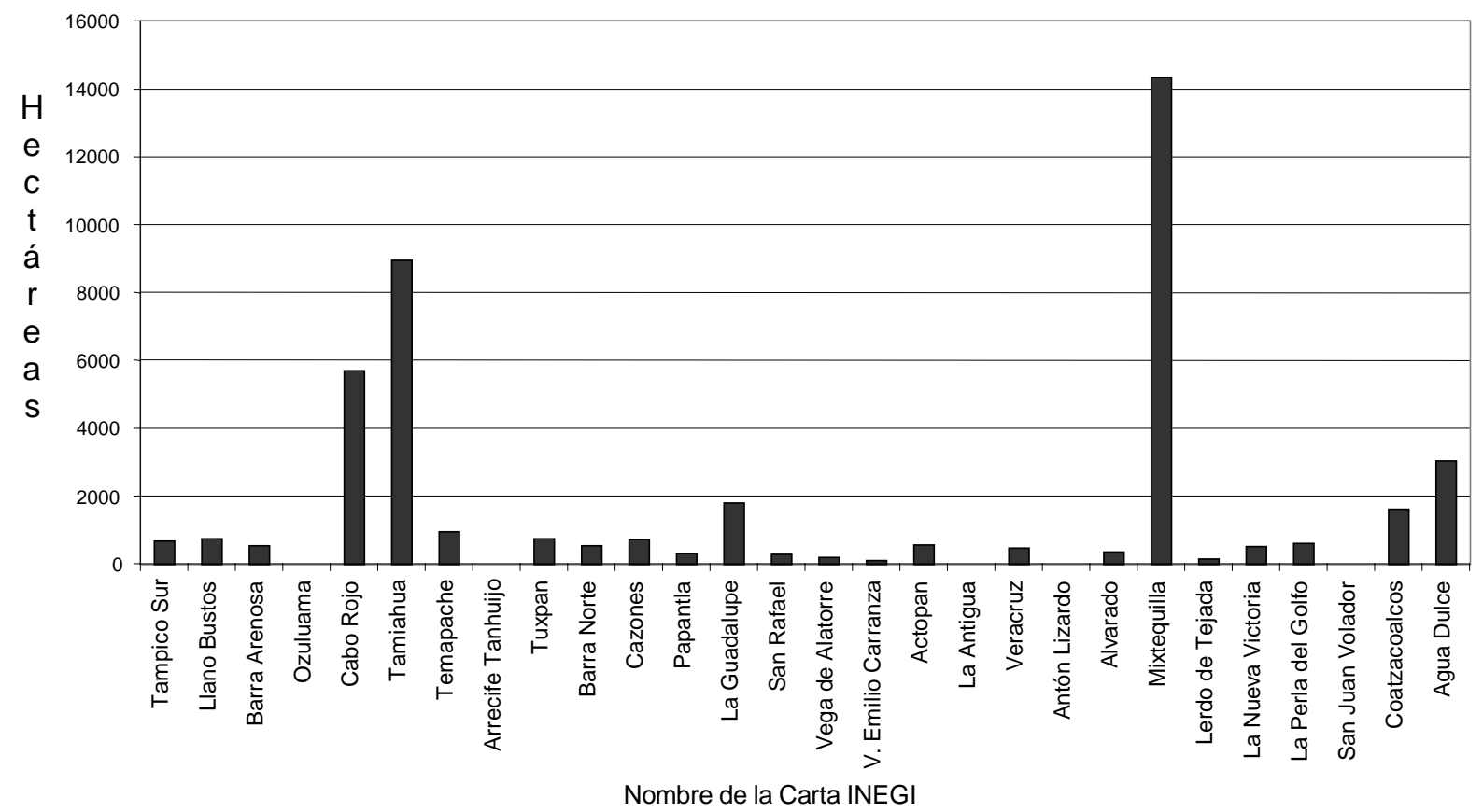

Figura 1. Área de manglar (en hectáreas) para cada una de las 28 cartas de INEGI a escala 1:50 000. El arreglo de las cartas es de norte a sur del estado.

En la figura 3 se muestran los límites geográficos de cada región hidrológica y la superficie total de manglar en cada una de estas regiones. En la Tabla 1 se mencionan los principales cauces, lagunas y estuarios, así como los tributarios secundarios asociados a cada cuenca hidrológica y la superficie total de manglar que corresponde a cada una de las cuencas (Tabla 3).

Región Hidrológica 26 (Pánuco). El sistema fluvial determinante es la cuenca del Río Pánuco, y de manera secundaria los Ríos Tamesí y Moctezuma. En esta región se ubica la Laguna de Pueblo Viejo con una extensión de 9090 ha, además de las numerosas lagunas de menor extensión interconectadas por diversos esteros (Tablas 1 y 3, Fig. 3).

Esta región presenta valores bajos con respecto a las otras, en extensión de la cuenca, en superficie de manglar y en descarga fluvial. Abarca una extensión de $11501 \mathrm{~km}^{2}(15.70 \%$ del total de las regiones hidrológicas presentes en el estado y el $13.43 \%$ del total de la superficie territorial estatal). La extensión total de manglar para esta región es de 661 ha que corresponden al $1.51 \%$ del total del estado. La descarga fluvial es de 14057 millones de metros cúbicos, lo que representa el $13.26 \%$ del total estatal.

Región Hidrológica 27 (Tuxpan-Nautla). Es la segunda región en extensión dentro del territorio veracruzano. El sistema fluvial determinante es la cuenca de los Ríos Tuxpan-Nautla, además de los cauces secundarios y sistemas lagunaresestuarinos asociados a esta región, entre ellos Tamiahua y otros de menor dimensión. Esta región se caracteriza por presentar las principales expresiones geomorfológicas del litoral como son las dunas e islas de barrera que se apoyan en arrecifes para formar extensos sistemas lagunares-estuarinos como Tamiahua y otros de menor dimensión (Tablas 1 y 3, Fig. 3). Ocupa el $25.70 \%$ del total de la superficie del territorio estatal. 
A. Área total de manglar por rango de extensión
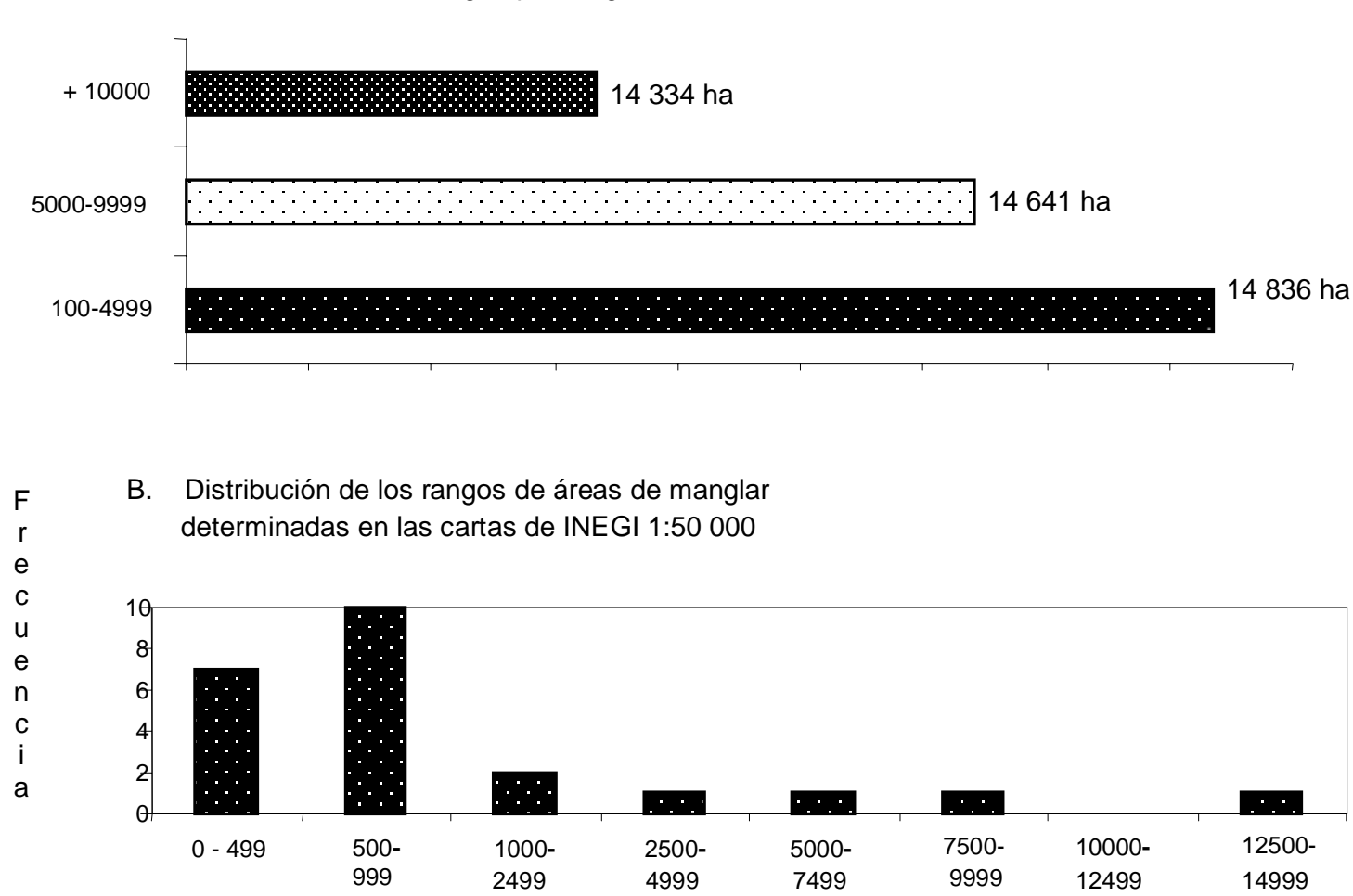

Rangos de área de manglar

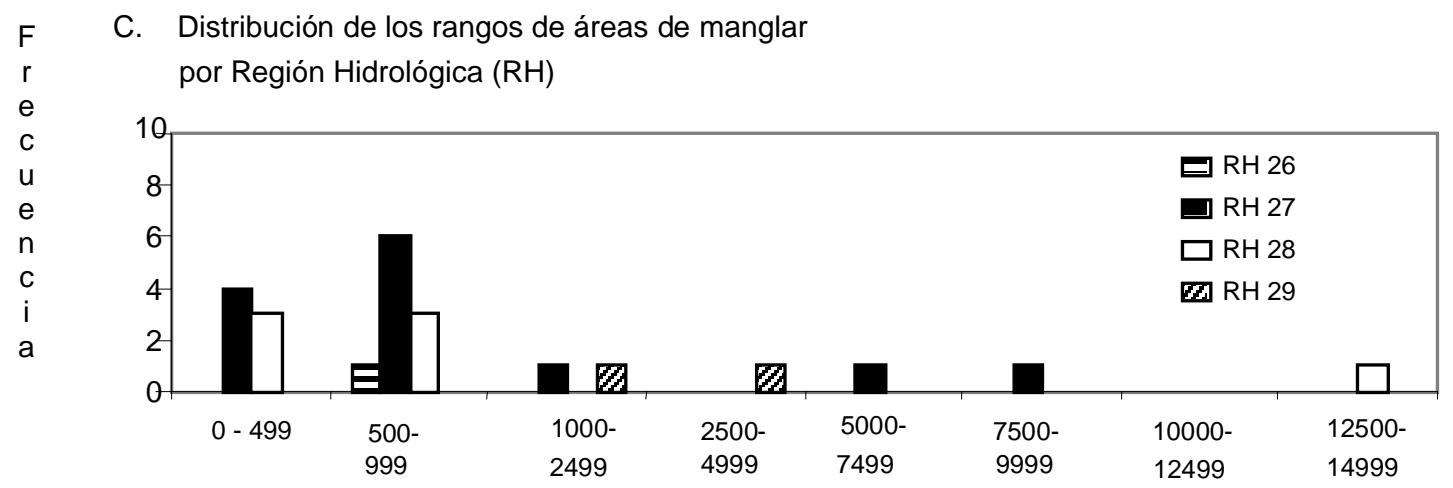

Rangos de área de manglar

Figura 2. A. Áreas totales de manglar en el estado de acuerdo con el área determinada en las fotografías aéreas y restituidas en las cartas de INEGI (escala 1:50 000) y agrupadas en tres rangos: de 0 ha a 5000 ha (34\%), de 5001 ha a 10000 ha (33\%) y de 10001 ha a 15000 ha (33\%). B. Número de áreas de manglar restituidas incluidas en diferentes rangos. C. Número de áreas de manglar restituidas en diferentes rangos para cada Región Hidrológica.

RH 26 = Pánuco, RH 27 = Tuxpan - Nautla, RH 28 = Papaloapan, RH 29 = Coatzacoalcos 
Tabla 2. Superficie de manglar determinada con imágenes de satélite a una escala de 1:250 000 para 1993 y de 1:125 000 para 2000. La secuencia de las cartas es de norte a sur

\begin{tabular}{lcclccc}
\hline $\begin{array}{c}\text { NOMBRE } \\
\text { CARTA } \\
\text { INEGI }\end{array}$ & $\begin{array}{c}\text { SUPERFICIE } \\
\text { MANGLAR } \\
\text { (ha) }\end{array}$ & POLÍGONOS & CLAVE & $\begin{array}{c}\text { SUPERFICIE POLÍGONOS CLAVE } \\
\text { MANGLAR } \\
\text { (ha) }\end{array}$ \\
\hline Tampico & 2443.04 & 16 & F14-3-6 & 1139.50 & 4 & F14-3-6 \\
Tamiahua & 10523.49 & 36 & F14-9 & 10262.60 & 16 & F14-9 \\
Poza Rica & 5371.86 & 19 & F14-12 & 5900.50 & 17 & F14-12 \\
Veracruz & 1759.17 & 5 & E14-3 & 1203.80 & 4 & E14-3 \\
Orizaba & 437.91 & 1 & E14-6 & & & \\
Coatzacoalcos & 25830.45 & 44 & E14-1-4 & 23618.70 & 27 & E15-4 \\
\hline \multicolumn{1}{c}{ Total } & 46365.92 & 121 & & 42125.10 & 68 & \\
\hline
\end{tabular}

Tabla 3. Magnitudes comparativas del área que cubren, descarga fluvial y área de manglar para cada Región Hidrológica de la vertiente del Golfo de México en el estado de Veracruz

\begin{tabular}{|c|c|c|c|c|c|c|c|c|}
\hline \multirow{2}{*}{$\begin{array}{c}\text { REGIÓN } \\
\text { HIDROLÓGICA } \\
(\mathrm{RH})\end{array}$} & \multicolumn{2}{|c|}{$\begin{array}{l}\text { ÁREA REGIÓN } \\
\text { HIDROLÓGICA }\end{array}$} & \multicolumn{2}{|c|}{$\begin{array}{l}\text { DESCARGA } \\
\text { FLUVIAL }\end{array}$} & \multicolumn{2}{|c|}{$\begin{array}{l}\text { ÁREA DE } \\
\text { MANGLAR }\end{array}$} & \multicolumn{2}{|c|}{$\begin{array}{l}\text { CAPTURA } \\
\text { PESQUERA }\end{array}$} \\
\hline & $\mathrm{km}^{2}$ & $\%$ & $\begin{array}{c}\mathrm{x} 10^{6} \mathrm{~m}^{3} / \\
\text { año }\end{array}$ & $\%$ & ha & $\%$ & $\mathrm{~T}$ & $\%$ \\
\hline Pánuco & 11501 & 15.79 & 14057 & 13.26 & 661 & 1.51 & 5163 & 5.93 \\
\hline Tuxpan-Nautla & 18259 & 25.07 & 14193 & 13.39 & 21544 & 49.17 & 22128 & 25.39 \\
\hline Papaloapan & 28636 & 39.32 & 44829 & 42.28 & 16947 & 38.69 & 50997 & 58.58 \\
\hline Coatzacoalcos & 14419 & 19.80 & 32941 & 31.07 & 4659 & 10.63 & 8745 & 10.04 \\
\hline
\end{tabular}

Comparativamente con las otras regiones hidrológicas, ésta ocupa el primer lugar en superficie de manglar y el tercer lugar en descarga fluvial. Cubre una extensión de $18259 \mathrm{~km}^{2}$ (25.07\% del total de las regiones en su parte veracruzana) y la extensión total de manglar para dicha porción es de 21544 ha que corresponde al $49.17 \%$ del total del estado; la descarga fluvial es de 14193 millones de metros cúbicos, lo que representa el $13.39 \%$ del total estatal.

Región Hidrológica 28 (Papaloapan). El sistema fluvial determinante es la cuenca del Río Papaloapan. Ocupa
$41.11 \%$ del total de la superficie territorial estatal (28 $636 \mathrm{~km}^{2}$, siendo $39.32 \%$ del total de las regiones), así como la mayor descarga de agua dulce (44 829 millones de metros cúbicos por año que representa el $42.28 \%$ para el estado). Su principal ecosistema estuarino es la Laguna de Alvarado que corresponde a la superficie de inundación costera más grande, pero también incluye otras lagunas de diversas magnitudes e importancia (Tablas 1 y 3, Fig. 3). Esta región ocupa el segundo lugar en superficie de manglar (16 947 ha que corresponde al $38.69 \%$ del total estatal. 


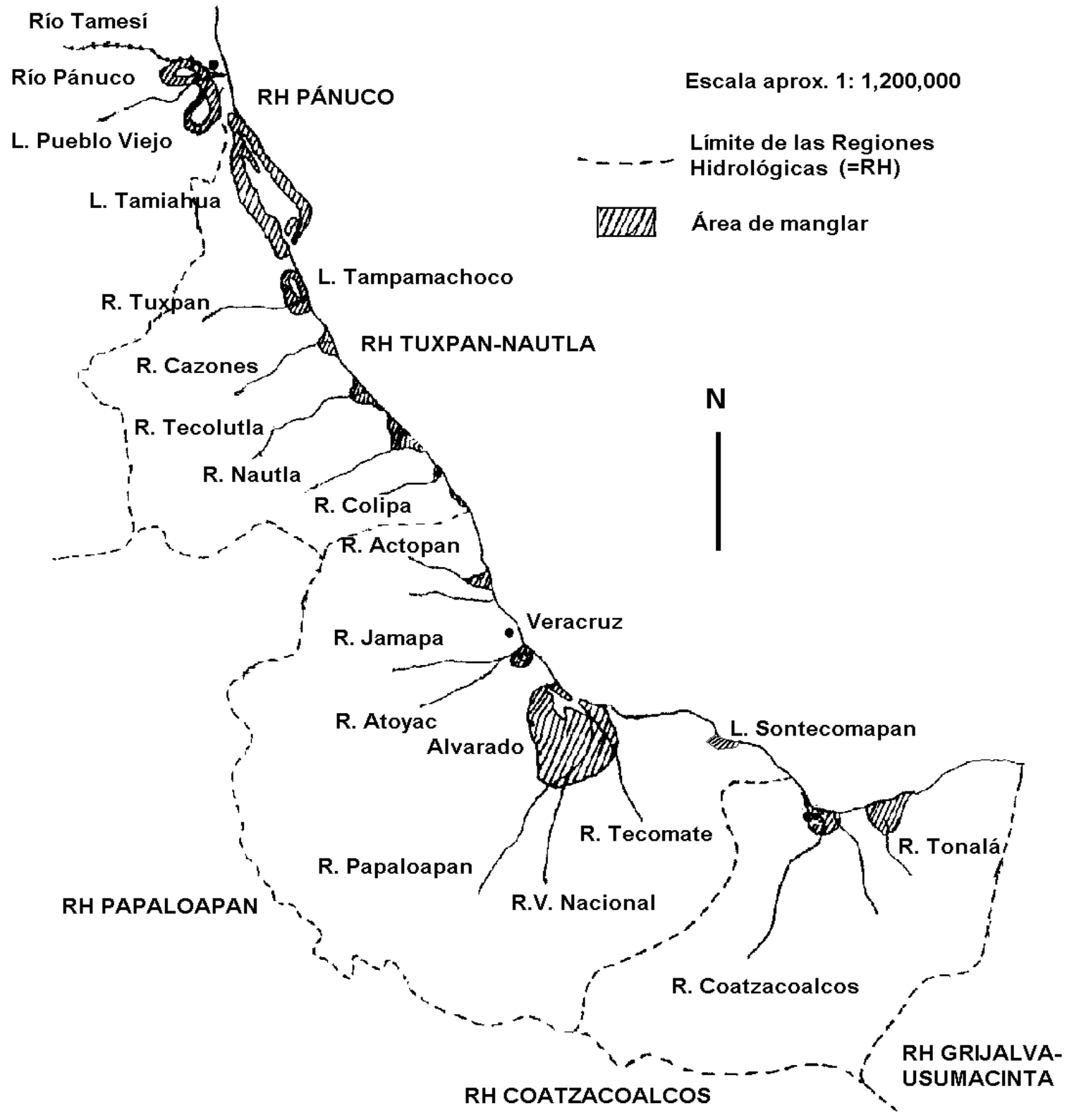

Figura 3. Distribución de las áreas de manglar en el litoral del estado de Veracruz.

Se delimitan las principales regiones hidrológicas $(\mathrm{RH})$ así como los cuerpos de agua asociados a ellas. 
Región Hidrológica 29 (Coatzacoalcos). Los principales aportes fluviales a esta región son el Río Coatzacoalcos y el sistema lagunar-estuarino de la Laguna del Ostión, pero también desembocan otros cauces (Tablas 1 y 3, Fig. 3). Esta región es la tercera en extensión dentro del territorio veracruzano $\left(14419 \mathrm{~km}^{2}, 19.80 \%\right.$ del total de las regiones y el $19.21 \%$ del total de la superficie territorial estatal), y ocupa el tercer lugar en superficie de manglar (4 659 ha que corresponde al $10.63 \%$ del total estatal) y el segundo lugar en descarga fluvial (32 941 millones de metros cúbicos, que representa el $31.07 \%$ ).

El análisis de la extensión de los manglares por rangos de superficies para cada una de las Regiones Hidrológicas se muestra en la figura 2B. En la región hidrológica Tuxpan-Nautla se encuentra el mayor número de superficies pequeñas de manglar (menores a las 1000 ha). Muchas de ellas están distribuidas en los principales sistemas lagunares del estado como son Tamiahua, Tampamachoco y San Agustín o en la boca de los ríos (Tabla 1). En la región hidrológica del Papaloapan se presenta un patrón similar al anterior, al encontrarse numerosas superficies pequeñas de manglar en los sistemas asociados al complejo lagunar de Alvarado y de Mandinga, además de otras de menor tamaño como La Mancha, Sontecomapan, El Llano, así como en las bocas de los ríos (Tabla 1, Fig. 2C). Distribución de manglar en los ecosis-
temas costeros de mayor superficie

En el estado de Veracruz, existen dos ecosistemas costeros con más de 10000 ha de manglar que corresponden a sistemas lagunares estuarinos con diferentes características.

Sistema lagunar de Tamiahua. Geomorfológicamente, se caracteriza por ser una costa de tipo acumulativo con áreas de dunas y playas bajas arenosas resguardadas por una gran isla de barrera que da origen a un extenso sistema lagunar-estuarino, la Laguna de Tamiahua (ver sección de geomorfología e hidrología). Esta laguna se ubica en la Región Hidrológica 27. La superficie aproximada de la laguna es de 79100 ha con 15909 ha de manglar. No cuenta con ningún sistema fluvial importante por lo que presenta una influencia predominantemente marina. Esto determina que las comunidades de manglar sean del tipo fisionómico de borde y cuenca, las cuales se caracterizan por un aporte fluvial bajo y por un lavado diario a causa de la fluctuación de la marea, lo que implica generalmente alta salinidad intersticial. En este tipo de bosques de manglar los árboles son de poco porte y talla mediana (7 m-10 m).

Sistema lagunar-estuarino de Alvarado. Este sistema lagunar estuarino es una depresión marginal de origen tectónico que se ubica en una región de subsidencia, que se ha incrementado por los procesos deltáicos. Recibe el aporte del Río Papaloapan, así como importantes sistemas fluviales asociados a la Región Hidrológica 28, lo que determina la presencia de extensos pantanos dulceacuícolas influenciados por la marea y de elevada productividad. Existe una gran barrera de dunas (ver sección de descripción geomorfológica) interrumpida por una amplia boca que conecta al mar a la Laguna de Alvarado. Ésta tiene una superficie aproximada de 11800 ha bordeada por 14364 ha de manglar. La boca de la laguna de Alvarado y las características geomorfológicas de la costa con escasa pendiente debido a la presencia de la llanura de inundación del Papaloapan, permiten una gran intrusión salina hacia el continente, lo que ha originado numerosas lagunas menores interconectadas por extensas redes fluviales.

Así mismo, las condiciones ambientales referidas determinan que los manglares sean del tipo fisionómico ribereño, los cuales se desarrollan a lo largo de las márgenes de los ríos, frecuentemente hasta el punto donde llega la máxima intrusión salina. En este tipo de 
bosques, los flujos de agua son intensos y el aporte fluvial rico en nutrimentos, así como la interacción entre la descarga fluvial y la influencia de la marea. Los bosques ribereños son los de mayor productividad de hojarasca y generalmente su salinidad intersticial es baja.

Relación de superficies de manglar, superficie de la cuenca y descarga fluvial identificadas para cada región hidrológica con la captura pesquera estatal.

A partir de los datos oficiales de la producción pesquera identificados para cada región hidrológica, se determinó la relación que existe entre ésta y la superficie de manglar, la superficie de las cuencas y la magnitud de la descarga fluvial (Tabla 3). La Tabla 4 proporciona los datos publicados por las dependencias oficiales (SEDAP, 1997) sobre la captura pesquera de los municipios correspondientes a cada región hidrológica así como sus porcentajes correspondientes.

En la figura 4 se señalan los porcentajes comparativos de estos datos, considerando al manglar como el principal factor relacionado con la magnitud de la producción pesquera. Sin embargo, no se observa una relación directa entre ambos aspectos ya que la mayor superficie de manglar ( $\mathrm{RH} 27$, Tuxpan-Nautla) no corresponde con la mayor producción pesquera ( $\mathrm{RH} 28$, Papaloapan).

En la Tabla 5 se indican los coeficientes de correlación entre la captura pesquera por región hidrológica con la cobertura de manglar, descarga fluvial y superficie de la cuenca, respectivamente. Se observa un alto coeficiente de correlación positiva significativa entre captura pesquera y la superficie de la cuenca, por lo que aparentemente la captura pesquera está determinada de manera importante por la superficie que comprende cada región hidrológica en el estado.
Tabla 4. Producción pesquera de cada Región Hidrológica a partir de los datos registrados para cada municipio costero (SEDAP, 1997)

\begin{tabular}{lcc}
\hline \multirow{2}{*}{ MUNICIPIOS } & \multicolumn{2}{c}{ PRODUCCIÓN } \\
& \multicolumn{2}{c}{ PESQUERA } \\
\cline { 2 - 3 } & Toneladas & $\%$ \\
\hline Pánuco & 5163 & 5.93 \\
Tamiahua & 5795 & 6.65 \\
Tuxpan & 4531 & 5.20 \\
Tecolutla & 7165 & 8.23 \\
Nautla & 738 & 0.84 \\
Vega de Alatorre & 3899 & 4.47 \\
Actopan & 738 & 0.84 \\
Veracruz & 4109 & 4.72 \\
Boca del Río & 2002 & 2.30 \\
Tlacotalpan & 1264 & 1.45 \\
Alvarado & 42884 & 49.27 \\
Coatzacoalcos & 8745 & 10.04 \\
\hline \multicolumn{1}{c}{ TOTAL } & 87033 & 99.94 \\
\hline
\end{tabular}

Fuentes de contaminación e impacto ambiental costero que afectan el manglar.

Asentamientos humanos y actividad turística. De los 210 municipios que conforman la entidad, 102 municipios se encuentran en altitudes menores a los 300 msnm, es decir, se localizan sobre la llanura costera de Veracruz. De estos, 28 son costeros ya que limitan directamente con el Golfo de México y conforman una superficie de $19161.15 \mathrm{~km}^{2}$ (26.46\% del total estatal) y concentran actualmente a 2035854 habitantes que representan más del $30 \%$ de la población del estado. La tasa anual de crecimiento en estos municipios es relativamente elevada, $6.6 \%$ (INEGI, 1997). En municipios como Boca del Río y Coatzacoalcos, existe una tasa anual de crecimiento superior al $9 \%$ y $7 \%$, respectivamente. 


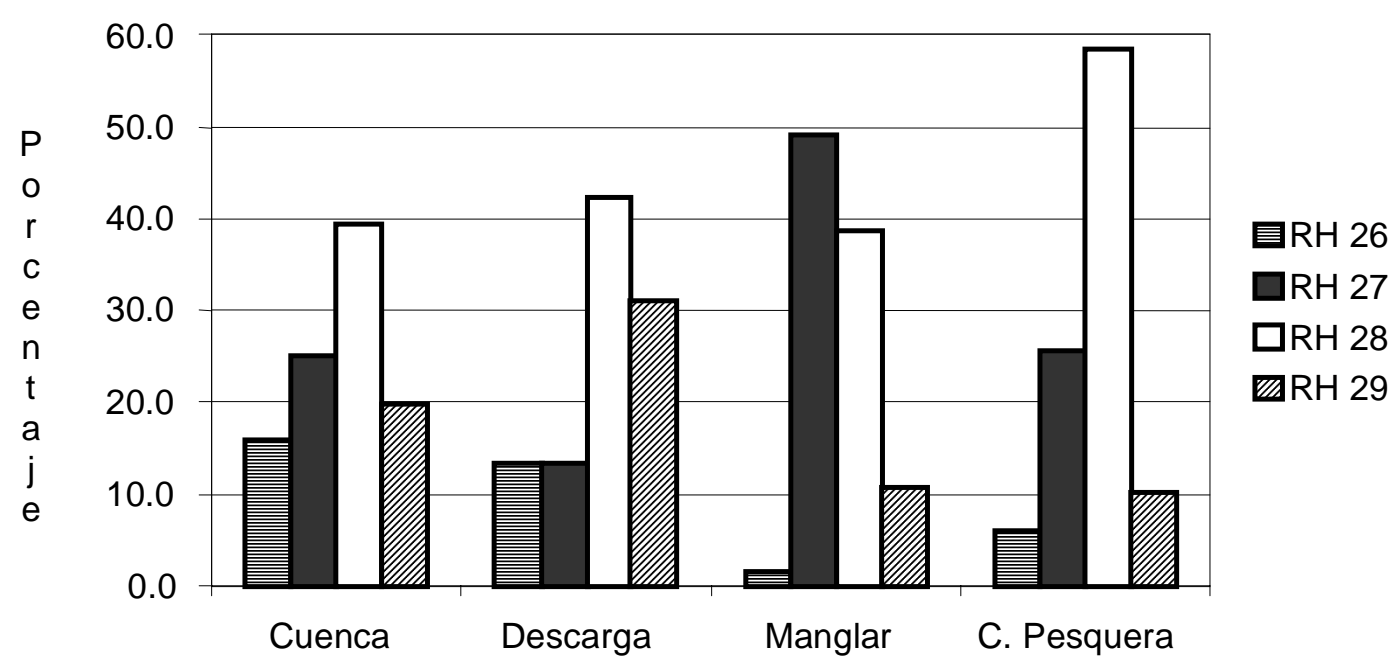

Figura 4. Porcentajes del área de la región hidrológica $(\mathrm{RH})$, descarga fluvial, área de manglar y captura pesquera para las cuatro regiones hidrológicas.

RH 26 = Pánuco, RH 27 = Tuxpan - Nautla, RH 28 = Papaloapan, RH 29 = Coatzacoalcos

Tabla 5. Coeficientes de correlación entre las principales características físicas de las cuencas hidrológicas y con las capturas pesqueras asociadas a cada una de ellas (los datos corresponden a la Tabla 3)

\begin{tabular}{llcccc}
\hline & & $\begin{array}{c}\text { ÁREA DE LA } \\
\text { CUENCA }\end{array}$ & $\begin{array}{c}\text { ÁREA DE } \\
\text { MANGLAR }\end{array}$ & $\begin{array}{c}\text { DESCARGA } \\
\text { FLUVIAL }\end{array}$ & $\begin{array}{c}\text { CAPTURA } \\
\text { PESQUERA }\end{array}$ \\
\hline $\begin{array}{l}\text { Área de } \\
\text { la cuenca }\end{array}$ & $\mathrm{R}$ & 1.0000 & & & \\
\hline Área de & $\mathrm{R}$ & 0.7018 & 1.0000 & & \\
manglar & $\alpha$ & 0.2982 & & & \\
\hline Descarga & $\mathrm{R}$ & 0.6958 & 0.0744 & 1.0000 & \\
fluvial & $\alpha$ & 0.3042 & 0.9256 & & 1.0000 \\
\hline Captura & $\mathrm{R}$ & 0.9960 & 0.6991 & 06551 & \\
pesquera & $\alpha$ & 0.0040 & 0.3009 & 0.3449 & \\
\hline
\end{tabular}


Con relación a la actividad turística, se localizan en la región 483 hoteles que ofertan un total de 15146 habitaciones (INEGI, 1997). Esta actividad y el crecimiento de zonas urbanas, inducen una presión sobre el uso del suelo y por lo tanto sobre la vegetación. En este caso es sobre los humedales y bosques de manglar que son rellenados para la construcción de viviendas e infraestructura turística, o talados para la obtención de materiales de construcción y carbón. De manera indirecta también reciben frecuentemente las descargas de los centros urbanos.

Solamente el $42.6 \%$ de las viviendas en los municipios costeros está conectada a la red pública, mientras que el resto vierte sus aguas negras a fosas sépticas, al mar, a ríos, lagunas o en grietas y barrancas. Tan sólo 10 de los 28 municipios costeros cuentan con plantas para el tratamiento de aguas negras. Estas plantas poseen una capacidad instalada para tratar $1412.6 \mathrm{l} / \mathrm{s}$ de aguas negras; sin embargo, en la práctica sólo es tratado un volumen de $1.60 \mathrm{l} / \mathrm{s}$ (INEGI, 1997). Esta situación ha inducido niveles de contaminación microbiológica críticos en la zona costera del estado, por lo que se ha alterado significativamente la calidad del agua de los ecosistemas lagunares y estuarinos, así como de los bosques de manglar asociados, como se muestra en la Tabla 6 (tomada de Wong y Barrera, 1996).

Industria petrolera y desarrollo industrial. En la zona costera del estado se localiza infraestructura petrolera de gran importancia en el ámbito nacional. Existen más de $3000 \mathrm{~km}$ de ductos que transportan diariamente a diversas refinerías del país más de 1073 millones barriles de petróleo y 2622 millones de pies cúbicos de gas. En la zona costera del estado, principalmente en la cuenca baja de los Ríos Coatzacoalcos y Tonalá, se concentra la mayor parte de la infraestructura petrolera e industrial de Veracruz. Existen seis plantas petroquímicas (Cosoleacaque, Cangrejera, Minatitlán, Morelos, Pajaritos y Poza Rica), donde se producen diariamente más de 330 mil barriles de productos petrolíferos y más de 14 mil toneladas de productos petroquímicos. También en la zona litoral están tres importantes campos petroleros (Agua Dulce, Poza Rica y Veracruz) donde se producen más de 107 mil barriles diarios de petróleo y 274 mil millones de pies cúbicos diarios de gas natural. Como apoyo al desarrollo petrolero e industrial del estado, en la zona costera hay cinco importantes puertos (Veracruz, Tuxpan, Coatzacoalcos, Pajaritos y Alvarado) que manejan un volumen anual de carga estimado en 50703500 t (INEGI, 1997).

Accidentes en las operaciones como rupturas de ductos, derrames de plataformas y accidentes de buques tanque, así como la transportación marítima y la descarga de aguas residuales industriales y municipales han ocasionado que en la zona costero-marina del estado, existan niveles de contaminación por hidrocarburos que rebasan considerablemente los limites permisibles definidos a escala internacional (Tablas 6 y 7). Incluso en regiones como Laguna del Ostión, Coatzacoalcos y el Río Tonalá, se registran las mayores concentraciones de hidrocarburos en agua y sedimentos costeros no sólo del Golfo de México sino del país. En los manglares asociados al Río Tonalá se han detectado niveles de hidrocarburos en sedimentos de 214 ppm y en hojas de manglar hasta de 3635 ppm (Botello y Toledo, 1996; Botello et al., 1996a y 1996b).

Actividades agropecuarias y forestales. De acuerdo con INEGI (1997), cerca de 1538167 ha se dedican a la agricultura y ganadería, y equivalen a un poco más del $80 \%$ de la superficie municipal costera. El aumento en la frontera agropecuaria, principalmente del cultivo de caña de azúcar, la ganadería bovina y las prácticas forestales han influido en la pérdida de vegetación costera, entre ella el bosque de manglar. Otro impacto ambiental asociado con la práctica de la agricultura y ganadería de tierras bajas, es la contaminación por agroquímicos en suelos, ríos, lagunas costeras, estuarios y organismos. 
Tabla 6. Niveles de contaminación microbiológica en aguas costeras del estado de Veracruz (Tomada de Wong y Barrera, 1996)

\begin{tabular}{|c|c|c|c|c|}
\hline LOCALIDAD & AÑO & $\begin{array}{c}\mathrm{CT} \\
\text { (miles) }\end{array}$ & $\begin{array}{c}\mathrm{CF} \\
\text { (miles) }\end{array}$ & REFERENCIA \\
\hline Laguna de Tamiahua & 1987-1988 & 10 & 10 & $\begin{array}{l}\text { Barrera et al., 1989a y } \\
1989 b\end{array}$ \\
\hline Estero Ciénega & 1988-1989 & 120 & 19 & Martínez y Barrera, 1990 \\
\hline Estero la Laja & $1989-1990$ & 10 & 10 & Maciel et al., 1990 \\
\hline Estero Cucharas & $1989-1990$ & 1.8 & 2.8 & Maciel et al., 1990 \\
\hline Puerto de Veracruz & 1981 & 1.1 & ND & Farías y Camargo, 1981 \\
\hline L. Alvarado & 1990 & 110 & & Ruiz et al.,1990 \\
\hline Región de Coatzacoalcos & & & & Rodríguez y \\
\hline Río & 1982 & 240 & 240 & 1987 \\
\hline Litoral & 1982 & 24 & 24 & \\
\hline Ciudad & 1982 & 0.24 & 0.24 & \\
\hline Laguna del Ostión & 1983 & 2.4 & 2.4 & \\
\hline Cosoleacaque & 1983 & 0.038 & 0.002 & \\
\hline \multirow[t]{2}{*}{ Minatitlán } & 1983 & 0.24 & 0.24 & \\
\hline & 1984 & 0.008 & 0 & \\
\hline Agua Dulce & 1984 & 0.24 & 0.038 & \\
\hline Las Choapas & 1984 & 0.24 & 0.038 & \\
\hline Nanchital & 1986 & 0.096 & 0.020 & \\
\hline Río Tonalá & 1983 & 24 & 38 & $\begin{array}{l}\text { Rodríguez y Botello, } \\
1987\end{array}$ \\
\hline $\begin{array}{l}\text { Límite permisible en agua } \\
\text { marina y estuarina, para } \\
\text { ser considerado como } \\
\text { adecuado para la } \\
\text { explotación de moluscos } \\
\text { bivalvos y acuacultura }\end{array}$ & & 0.070 & 0.014 & SEDUE, 1989 \\
\hline $\begin{array}{l}\text { Límite permisible en agua } \\
\text { estuarina para actividades } \\
\text { recreativas con contacto } \\
\text { primario }\end{array}$ & & & 0.200 & SEDUE, 1989 \\
\hline $\begin{array}{l}\text { Límite permisible en agua } \\
\text { marina para actividades } \\
\text { recreativas con contacto } \\
\text { primario }\end{array}$ & & 1.000 & & SEDUE, 1989 \\
\hline
\end{tabular}

$\mathrm{CT}=$ coliformes totales $\mathrm{CF}=$ coliformes fecales 
Tabla 7. Niveles de contaminación por hidrocarburos en el agua, sedimentos y organismos marinos de la zona costera de Veracruz

\begin{tabular}{|c|c|c|c|c|}
\hline LOCALIDAD & $\begin{array}{l}\text { AGUA } \\
(\mathrm{ppb})\end{array}$ & $\begin{array}{l}\text { SEDIMENTOS } \\
(\mathrm{ppm})\end{array}$ & $\begin{array}{l}\text { ORGANISMOS } \\
(\mathrm{ppm})\end{array}$ & REFERENCIA \\
\hline L. de Pueblo Viejo & & 53.0 & & Botello y Macko, 1982 \\
\hline L. de Tamiahua & & 31.0 & & Botello y Macko, 1982 \\
\hline L. de Alvarado & & 18.0 & & Botello y Macko, 1982 \\
\hline L. del Ostión & 18.4 & 120.0 & 850.0 & $\begin{array}{l}\text { Botello y Páez, } 1984 \text { y } \\
\text { 1986; Botello et al., } \\
\text { 1996a y b }\end{array}$ \\
\hline Río Coatzacoalcos & 14.0 & 680.0 & $6.0 a, 1.8 b, 7.5 c$ & $\begin{array}{l}\text { Botello et al., 1996a y b; } \\
\text { Toledo et al., } 1989\end{array}$ \\
\hline Río Tonalá & 9.0 & 1148.0 & & $\begin{array}{l}\text { Toledo, 1988; Toledo et } \\
\text { al., } 1989\end{array}$ \\
\hline Río Tuxpan & 20.9 & & & Botello et al., 1996a y b \\
\hline Puerto Veracruz & 14.0 & & & Botello et al., 1996a y b \\
\hline Límite permisible & 10.0 & 70.0 & & UNESCO, 1976 \\
\hline
\end{tabular}

a peces; b crustáceos; c moluscos

\section{DISCUSIÓN}

Este planteamiento y los resultados obtenidos refuerzan la necesidad de aproximarse a la conservación de los bosques de manglar desde una perspectiva integral de cuenca, y no de manera aislada, a partir de un ecosistema o de una actividad.

Los manglares de Veracruz no son los más importantes en extensión del Golfo de México ya que sólo constituyen el $14 \%$ de los 6 estados que lo bordean. Sin embargo, desempeñan un papel ecológico importante en los bienes y servicios que proporcionan a lo largo de toda la extensión del litoral veracruzano por lo que cobran un gran valor. Estos incluyen: protección y estabilización de la línea de costa, criaderos para numerosos recursos pesqueros económicamente importantes y como una variada fuente de productos que proporcionan a las poblaciones costeras en forma de leña, madera y carbón (Yáñez y Lara, 1999).
El tamaño y tipo estructural de manglares varía de manera importante a lo largo del litoral. Para poder interpretar los resultados obtenidos referentes a la superficie de manglar en la costa del estado de Veracruz, es necesario considerar que la existencia de este tipo de vegetación depende de diversos factores. Los principales son el clima, el balance hidrológico entre la influencia mareal y la descarga de agua dulce proveniente de tierras altas, así como la geomorfología y la dinámica costera.

Aunque los manglares se desarrollan en medios influenciados por agua salada, para su desarrollo normal requieren de otros factores como el aporte de agua dulce que les permite mantener un adecuado balance iónico y aprovechar la carga de nutrimentos del aporte continental. Walsh (1974) plantea que el manglar se desarrolla en mayor grado donde se conjuntan temperaturas cálidas (donde el promedio del mes más frío exceda los $20^{\circ} \mathrm{C}$ y la variación anual sea 
menor de $5^{\circ} \mathrm{C}$ ), gran descarga fluvial y sustratos aluviales con alta disponibilidad de nutrimentos (predominen lodos finos ricos en materia orgánica), al resguardo del oleaje y marejadas y por tanto protegidos de la erosión marina, en presencia de salinidades que varían entre 5 y 30\% y con una amplia fluctuación de marea y un declive reducido que permitan la intrusión de agua salada a grandes distancias tierra adentro. En condiciones ambientales sub-óptimas el manglar no alcanza su mayor desarrollo estructural. Las distintas condiciones a lo largo del litoral veracruzano han permitido el desarrollo de diferentes tipos de bosques de manglar que ocupan ambientes y superficies muy variadas. Estas diferencias necesariamente se reflejan en su productividad y en los aportes de nutrimentos que hacen a los cuerpos de agua.

Otro factor de variación a lo largo de la costa es la estacionalidad de la descarga de agua dulce. Existen lagunas costeras (y ríos) con bocas efímeras que se cierran durante una parte del año. Ejemplo de ello son las Lagunas del Llano y de la Mancha y el Río Limón, en la región hidrológica del Papaloapan. Ello implica que la descarga de nutrimentos al mar es estacional y que al inicio de la temporada de lluvias, cuando se rompen las barras, es de gran magnitud. El impacto del aporte de nutrimentos permanente versus estacional no ha sido analizado para las pesquerías de la costa veracruzana.

Los cálculos de superficie presentados en este trabajo, indican que el manglar cubre 43811 ha con fotografías aéreas multitemporales de 1975, 1976 y 1980 (escala 1:250 000). Presentan una diferencia de 2236 ha con el área determinada para 1993, de 46047 ha (escala 1:250 000; Ortiz y Méndez, 2000). Estas diferencias se deben principalmente a la restitución de la fotografía a diferente escala. Esto es evidente también en las imágenes de satélite con las que se elaboró el Inventario Forestal Nacional 2000 (Palacios et al., 2000) que registra un área de $392 \mathrm{~km}^{2}$ (39 $200 \mathrm{ha}$ ) con una escala de 1:250 000, mientras que la superficie determinada en este estudio con las mismas imágenes es de 42125.1 ha pero a escala 1:125000 (Tabla 2), resultando en una diferencia es de 2925 ha. En primer lugar, hay que tener en consideración los cambios de escala con el que se realiza cada una de las restituciones, así como la digitalización de cada persona ya que pueden tener apreciaciones diferentes.

Los valores de área de manglar fluctúan entre 39200 ha (imágenes de satélite, escalas 1:250 000) y 46047 ha (fotografía aérea de 1993, a la escala 1:250 000). El valor obtenido en el presente trabajo es intermedio de 42125 ha, que es algo menor al reportado recientemente en el Simposio de Áreas Naturales Protegidas con un área de manglar de 46127 ha para la costa veracruzana (Challenger-SEMARNAT, 2002). Por lo tanto, para afinar este valor se requeriría un gran esfuerzo de verificación de campo y fotografías a menor escala.

Así mismo, los valores obtenidos contrastan con los cálculos presentados por Loa (1994) de 18162 ha. Esta diferencia puede deberse en parte a que en el estado se encuentran numerosos cuerpos de agua rodeados por pequeñas superficies de manglares y no solamente los grandes sistemas como el de Alvarado y Tamiahua (Figuras $2 \mathrm{~A}$ y $2 \mathrm{~B}$ y 3 ), así como también la metodología que cada autor siguió (Ortiz y Méndez, 2000).

La variación del área de manglar mencionada por diferentes autores a lo largo del tiempo para el litoral de Veracruz dificulta calcular la tasa de pérdida. Por ejemplo, las áreas de manglar registradas en el Inventario Nacional de Gran Visión de 1991 (SARH, 1991) y los Resultados del Inventario Forestal Nacional 2000 (Palacios et al., 2000) estiman que en el estado en 9 años se han perdido 18513 ha $(7.8 \%)$ lo que corresponde a una tasa anual de 2057 ha. Sin embargo, esto 
puede ser aproximado para áreas determinadas como por ejemplo el manglar que rodea la Laguna de Sontecomapan en la cual Dirzo (1995) señala una tasa anual de pérdida de manglar del $2 \%$ que se relaciona con el establecimiento de pastizales para ganado bovino. En la región de La Mancha, mencionan una tasa promedio de pérdida de manglar de $1.12 \%$ para Avicennia germinans y de $4.54 \%$ para Laguncularia racemosa.

Con los datos mínimo (42 125.1 ha) y máximo (46 365.92 ha) calculados en el presente estudio en Veracruz, y con las reservas pertinentes debido a las consideraciones debidas a la restitución que anteriormente se discutió, se estima que aproximadamente 4240.8 ha de área de manglar se han perdido, lo que representa el $9.6 \%$ La especie Conocarpus erectus (botoncillo) es la más afectada en el estado de Veracruz. Esta especie se localiza en las zonas colindantes con actividades agropecuarias, donde la inundación y la salinidad tienen menor impacto. Por lo tanto es la primera en verse afectada por la extensión de los campos productivos.

Los datos muestran que la deforestación en las áreas de manglar de la entidad, puede fluctuar entre $1.12 \%$ y $9.63 \%$ de acuerdo a lo anteriormente discutido. Esto puede ser atribuido principalmente al desarrollo agrícola 0 ganadero que el estado ha experimentado en los últimos años. Por otro lado, estas áreas son poco propicias para los asentamientos humanos, ya que están permanentemente inundadas. Esto último contrasta fuertemente con la población de Isla del Carmen en Campeche, donde la demanda de espacios urbanos ha impactado inicialmente a las áreas de cultivo adyacentes a la ciudad y a los bosques de manglar en el litoral interno de la isla. Las consecuencias son dramáticas ya que el desmonte para relleno de pantanos con basura industrial y urbana, para ampliar las áreas de asentamientos, esta propiciando condiciones de insalubridad, aumentando la contaminación orgánica por desechos domésticos, reincorporación de contaminantes a la columna de agua anteriormente retenidos en los sedimentos de los manglares, disminución de la productividad natural del sistema y el abatimiento de los recursos pesqueros asociados a los manglares y a la Laguna de Términos (Yáñez y Benítez, 1991). Estos resultados refuerzan la necesidad de establecer una regulación para la conservación de los bosques de manglar desde una perspectiva integral, y no de manera aislada, a partir de un ecosistema o de una actividad económica.

Es importante destacar que la distribución de los manglares en el estado de Veracruz es principalmente en superficies pequeñas menores de 5000 ha y sólo en las lagunas de Tamiahua y Alvarado se registran superficies mayores a 10000 ha. No obstante, estas superficies pequeñas presentan características de diversidad y estructura similar a las de las grandes superficies. De aquí la importancia de proteger y conservar estas áreas puesto que preservando sus funciones ecológicas, también se mantiene su función de protección de la línea de costa en el estado de Veracruz, la cual se encuentra en constante modificación por los procesos costeros tan dinámicos causados por los eventos de invierno denominados nortes, y por los huracanes durante el verano, entre otros.

Asimismo, de acuerdo con Arriaga et al. (2000), la Región de Tamiahua, representa el límite norte en el litoral del Golfo de México de un manglar extenso y bien estructurado. Está extensión de manglar es la más grande que aún se conserva al norte del Río Papaloapan. Por otra parte, las lagunas de la región de Alvarado corresponden ecológicamente a la porción superior del estuario, y de acuerdo con Rojas et al. (1992), quedan comprendidas bajo el término de sistemas fluvio-lagunardeltáico-estuarinos.

Los datos de captura pesquera analizados adolecen de la misma problemática general que el resto de este tipo de 
datos en el ámbito nacional, esto es, ignoran valores que pueden ser determinantes para su interpretación. No toman en consideración la pesca de autoconsumo, que es de gran importancia en varios de los sistemas, sobre todo los de menor tamaño. Aunado a ello está la falta de informes de capturas por parte de los pescadores a las autoridades locales. Sin embargo, se considera que los valores utilizados representan la tendencia general existente entre magnitud de pesquerías, superficie de manglar y cuerpos de agua así como de descargas.

Con base en lo anterior, este análisis permite ratificar que la magnitud de las pesquerías y la productividad del manglar no depende exclusivamente de un solo factor ambiental (en este caso la superficie de manglar), sino que en realidad es la consecuencia ecológica de procesos costeros mucho más complejos que han sido referidos como mecanismos de producción (Soberón et al., 1986 y Yáñez et al., 1994). A lo largo del área de la cuenca hidrológica se incluyen numerosos factores y procesos, entre ellos la descarga de los ríos, la superficie de lagunas costeras y estuarios, y el rango de mareas que actuando conjuntamente como mecanismos naturales son determinantes en la producción pesquera. Otro factor, puede ser atribuido a las diferencias que pueden existir en el esfuerzo de pesca por cuencas hidrológicas.

La región pesquera de mayor importancia en el estado es la del Papaloapan (Región Hidrológica 28). Ésta se caracteriza por presentar la mayor área de la cuenca, mayor descarga fluvial así como una gran extensión de manglar. Al respecto, cabe destacar que en esta región domina el manglar de tipo ribereño asociado a la Laguna de Alvarado, que se caracteriza por su alta productividad (Twilley y Day, 1999). Esta productividad junto con la mayor magnitud de descarga y la mayor penetración de la influencia mareal, comparativamente con las otras regiones hidrológicas, determina una mayor exportación de nutrimentos a la zona marina adyacente y por consecuencia una mayor productividad pesquera (Tablas 3, 4 y 5). Asimismo, esta región hidrológica también presenta la mayor densidad de población; sólo en los municipios costeros asociados a la laguna de Alvarado la población es de 240198 habitantes, por lo que podría existir un esfuerzo pesquero mayor que deberá ser incorporado como parte de las variables que determinan las capturas pesqueras. Este volumen de población también representa probablemente un mayor uso extractivo y destructivo del manglar (Portilla et al., 1998, Vázquez et al., 1998).

Asimismo, la actividad pesquera también ha sufrido importantes alteraciones debido a la sobreexplotación de ciertos grupos de organismos, a la creciente contaminación en el medio acuático, y a la pérdida de hábitats costeros esenciales para el ciclo de vida de las especies con importancia económica, como son lagunas costeras, los bosques de manglar o pastos marinos. La pesca ribereña comercial y de autoconsumo se lleva a cabo principalmente en las lagunas costeras, que de acuerdo con los datos presentados en las Tablas 6 y 7 indican que hay un fuerte deterioro en la salud de los ecosistemas costeros. Por lo tanto, la pesquería también puede estar influenciada fuertemente por estos impactos ambientales.

El crecimiento de zonas urbanas y el desarrollo de actividades productivas como son la extracción, procesamiento y distribución de hidrocarburos, las actividades portuarias, industriales, pesqueras y agropecuarias, la generación de energía eléctrica, y el desarrollo turístico, entre las más importantes, han causado un deterioro ambiental significativo en la zona costera del estado, sus ecosistemas y sus recursos naturales (Botello y Toledo, 1996; Botello et al., 1996a y b; Silva y Botello, 1996; Toledo et al., 1989; Villanueva y Páez, 1996; Wong y Barrera, 1996).

La alteración en la calidad del agua de estos ecosistemas potencialmente 
puede ocasionar serios problemas de salud pública y afectaciones de activi-dades como la acuacultura, la pesca y el turismo, si se toma en cuenta que los niveles de grupos bacterianos registrados, rebasan considerablemente en muchos casos, los niveles permisibles establecidos por la normatividad mexicana (Botello et al., 1996a y b; Wong y Barrera, 1996).

Por otro lado, en los manglares asociados al Río Tonalá se han detectado niveles altos de hidrocarburos lo que implica que no sólo se trata de una alteración crítica en la calidad ambiental de las lagunas, estuarios y manglares del estado, sino un riesgo muy importante para la salud humana (Botello y Toledo, 1996; Botello et al., 1996a y b).

La extensa infraestructura que existe en la entidad particularmente la gran extensión de ductos puede inducir impactos ambientales, como son la alteración del drenaje superficial en zonas de humedales y manglares al conformar barreras al flujo de agua y sedimentos, afectación de la hidrología de las lagunas costeras y por lo tanto de los propios manglares, salinización de tierras e inundación de terrenos.

Finalmente, la generación de desechos líquidos y sólidos por el sector petrolero, industrial y portuario, ha hecho que en lagunas costeras y estuarios (muchos de los cuales se encuentran bordeados por bosques de manglar), se registren niveles de metales pesados en agua, sedimentos y organismos que rebasan los límites permisibles por la normatividad mexicana y por la de países como Australia, Estados Unidos y Japón (Botello et al., 1996b; Toledo et al., 1989; Villanueva y Páez, 1996).

A lo largo de las últimas décadas y debido al impulso a la ganadería en primer lugar y al cultivo de arroz en segundo, en Veracruz se ha perdido un importante porcentaje del manglar. Otro impacto ambiental asociado con la práctica de la agricultura y la ganadería de tierras bajas, es la contaminación por agroquímicos de suelos, ríos, lagunas costeras y estuarios. Benítez y Bárcenas (1996) registran para las regiones agrícolas costeras del estado, la aplicación al menos de 1375.37 t de ingredientes activos de plaguicidas. Como es de esperarse, se han detectado niveles elevados de agroquímicos en sedimentos y organismos de ecosistemas costeros de Veracruz (Botello et al., 1996a; Viveros y Albert, 1996).

\section{CONCLUSIONES}

Estos resultados permiten destacar la necesidad e importancia de considerar la conservación de los bosques de manglar dentro de una visión de manejo integral de la zona costera de Veracruz. Se deberá evitar no solamente la tala de manglar, sino también y con igual grado de atención tratar de preservar la magnitud, temporalidad y calidad de la descarga fluvial por su efecto directo sobre la geomorfología y la vegetación costera, así como sobre la magnitud y persistencia de los recursos pesqueros estatales.

\section{REFERENCIAS}

Arriaga, C.L.; J.M. Espinosa R.; C. Aguilar Z.; E. Martínez R.; L. Gómez M. y E. Loa L. 2000. Regiones terrestres prioritarias de México. Comisión Nacional para el Conocimiento y Uso de la Biodiversidad (CONABIO). México D.F. 609 p.

Barrera, E.G.; A.T. Castañeda; J.M. Díaz; C.E. Ducoing y F.M. Martínez. 1989a. Relación entre parámetros ambientales y bacterias indicadoras de contaminación fecal. Res. In: VIII Coloquio de Investigación ENEPIztacala, Universidad Nacional Autónoma de México. Febrero. C-26. 
Barrera, E.G.; J.M. Díaz; F.M. Martínez; R.P. Ramírez; Ch.E. Ducoing y V.C. Rosas. 1989b. Evaluación de la calidad sanitaria en agua y sedimentos de la Laguna de Tamiahua, Veracruz. In: III Congreso Latinoamericano sobre Ciencias del Mar. Cumaná, Venezuela. p: 45.

Benítez, J. y C. Bárcenas P. 1996. Patrones de uso de los plaguicidas en los ecosistemas costeros. In: A.V. Botello; J.L. Rojas G.; J. Benítez y D. Zárate L., eds. Golfo de México, Contaminación e Impacto Ambiental: Diagnóstico y Tendencias. EPOMEX Serie Científica 5. Universidad Autónoma de Campeche. México. p:155-167.

Botello, A.V. y A. Toledo O. 1996. Impacto ambiental de la industria petrolera en el Río Coatzacoalcos, Veracruz. In: A.V. Botello; J.L. Rojas G.; J. Benítez y D. Zárate L., eds. Golfo de México, Contaminación e Impacto Ambiental: Diagnóstico y Tendencias. EPOMEX Serie Científica 5. Universidad. Autónoma de Campeche. México. p:541-554.

Botello, A.V. y S. Macko, 1982. Presencia de hidrocarburos fósiles (n-parafinas) en sedimentos recientes de lagunas costeras en el Pacífico de México. Anales Centro Ciencias del Mar y Limnología. Universidad Nacional Autónoma de México. 7(1):159-168.

Botello, A.V. y F. Páez O. 1984. Evaluación geoquímica del Río Coatzacoalcos y áreas adyacentes, 1982-1983. Informe Final presentado al Centro de Ecodesarrollo, Instituto de Ciencias del Mar y Limnología, Universidad. Nacional Autónoma de México. 168 p.

Botello, A.V. y F. Páez O. 1986. El problema crucial: La contaminación. Centro de Ecodesarrollo, Vol. I. Serie Medio Ambiente en Coatzacoalcos. CECODES, México, D. F. 177 p.
Botello, A.V.; G. Ponce V.; A. Toledo; G. Díaz G. y S. Villanueva, 1996a. Ecología, recursos costeros y contaminación del Golfo de México. In: A.V. Botello; J.L. Rojas G.; J. Benítez y D. Zárate L., eds. Golfo de México, Contaminación e Impacto Ambiental: Diagnóstico y Tendencias. EPOMEX Serie Científica 5. Universidad Autónoma de Campeche. México. p:25-44.

Botello, A.V.; G. Ponce y S.A. Macko, 1996b. Niveles de concentración de hidrocarburos en el Golfo de México. In: A.V. Botello; J.L. Rojas G.; J. Benítez y D. Zárate L., eds. Golfo de México, Contaminación e Impacto Ambiental: Diagnóstico y Tendencias. EPOMEX Serie Científica 5. Universidad. Autónoma de Campeche. México. p:225-253.

Childers, D.; J.W. Day y R. Miller. 1990. Relating climatological forcing to coastal water levels in Louisiana estuaries and the potential importance of El Niño - Southern Oscillation events. Climate Research, 1:31-42

Cintrón, G.; A.E. Lugo y R. Martínez, eds. 1980. Structural and functional properties of mangrove forests. A Symposium Signaling The Completion of the Flora of Panama. Universidad de Panamá. 168 p.

Cintrón, G.M. e Y. Schaeffer N. 1992. Ecology and management of new world mangrove. In: U. Seeliger, ed. Coastal Plant in Latin America. Academic Press. San Diego. p:233-258.

Dirzo, R., 1995. Los Tuxtlas: una reserva de la Biosfera. Seminario Los Tuxtlas: Conservación y Desarrollo Sustentable. Informe Ejecutivo. Catemaco, Veracruz. 56 p.

Farias, S. A. y F. Camargo. 1981. Estudio preliminar sobre la contaminación de bacterias en el Puerto de Veracruz, 
Ver. In: VIII Simposio Latinoamericano sobre Oceanografía Biológica. Acapulco, Gro, México. p:661-674.

Flores, G.M; J. Jiménez; X. Madrigal; F. Moncayo y F. Takaki. 1971. Memorias del mapa de tipos de vegetación de la República Mexicana. Secretaría de Recursos Hidráulicos. México. 208 p.

Flores V., F.; F. González F.; D.S. Zamarano y P. Ramírez G. 1992. Mangrove ecosystems on the Pacific coast of México: Distribution, structure, litterfall and detritus dynamics. In: U. Seeliger, ed. Coastal Plant Communities of Latin America. Academic Press, Inc. San Diego. p:269-288.

Haines, E.B. 1979. Interactions between Georgia salt marshes and coastal waters: a changing paradigm. In: R.J. Livingston, ed. Ecological Processes in Coastal and Marine Systems. Plenum Press. Mar. Sci. Nueva York. p:35-46.

Hofstetter, R.H. 1988. Vegetational changes in southern Florida wetlands in relation to anthropogenic. In: G. Cintrón; A.E. Lugo y R. Martínez, eds. 1980. Structural and functional properties of mangrove forests. A Symposium Signaling The Compleion of the Flora of Panama. Universidad de Panamá. 168 p

Instituto Nacional de Geografía, Estadística e Informática (INEGI), 1997. Anuario Estadístico del Estado de Veracruz. Instituto Nacional de Geografía, Estadística e Informática. Gobierno del Estado de Veracruz. Edición 1997. Vol. I y II. 1092 p.

Kjerfve, B.; L.D. de Lacerda; C.E. Rezende y A.R. Coelho O. 1999. Hydrological and hydrogeochemical variations in mangrove ecosystems. In: A. Yáñez A. y A.L. Lara D., eds. Ecosistemas de Manglar en América
Tropical, Instituto de Ecología A.C. México. UICN/ HORMA, Costa Rica. NOAA/NMFS Silver Spring, MD. EUA. p:71-82.

Kushlan, J.A. 1988. Impact of water management on wildlife in the Florida Everglades. In: Ecología y Conservación del Delta de los Ríos Usumacinta y Grijalva, INIREBDivisión Regional Tabasco y Gobierno del Estado de Tabasco. p:231-243.

Lahmann, E.J.; S.C. Snedaker y M.S. Brown, 1987. Structural comparisons of mangrove forests near shrimp ponds in southern Ecuador. Interciencia 12(5):240-243.

Loa, E.L. 1994. Los manglares de México: sinopsis general para su manejo. In: D.O. Suman, ed. El ecosistema de manglar en América Latina y la Cuenca del Caribe: su manejo y conervación. Miami, Florida. p:44-151.

Lugo A.E. y S.C. Snedaker. 1974. The ecology of mangroves. Annual Review of Ecology and Systematics 5:39-54.

Maciel, P.G.; M. Vicencio; P. Martínez; G. Barrera; E. Ducoing y P. Ramírez, 1990. Contaminación bacteriana de los esteros La Laja y Cucharas de la Laguna de Tamiahua, Ver. In: VIII Congreso Nacional de Oceanografía. Universidad Autón. de Sinaloa, México. p:38.

Martínez, F.M. y G.E. Barrera, 1990. Influencia de las mareas en la calidad bacteriológica del estero $\mathrm{La}$ Ciénega, Tamiahua, Veracruz. In: VI Curso Simposio Internacional sobre la Biología de la Contaminación, ENEP-Iztacala Universidad Nacional Autónoma de México. p:18.

Medina, E., 1999. Mangrove physiology: the challenge of salt, heat and light stress under recurrent flooding. In: A. Yáñez A. y A.L. Lara D., eds. 
Ecosistemas de Manglar en América Tropical, Instituto de Ecología A.C. México. UICN/ HORMA, Costa Rica. NOAA/NMFS Silver Spring, MD. EUA. p:106-126.

Odum, H.T. 1967. Work circuits and system stress. In: H.E. Young, ed. Simposium on Primary Productivity and Mineral Cycling in Natural Ecosystems. University of Maine Press. Orono, Maine. p:81-138.

Olsen, S.; L. Arriaga y G. Foer. 1989. Actualización. In: S. Olsen y L. Arriaga, eds. Establishing a Sustainable Shrimp Mariculture Industry in Ecuador. The University Rhode Island. Coastal Resources Center. p:xi-xv.

Ortiz P., M.A. y P. Méndez L. 2000. Componentes naturales y de uso del suelo vulnerables a las variaciones del nivel del mar en la costa Atlántica de México. Investigaciones Geográficas. Instituto de Geografía. Univ. Nacional Autónoma de México 41:55-68.

Palacios P., J.L.; G. Bocco; A. Velásquez; J.F. Mass; F. Takaki; A. Victoria; L. Luna G.; G. Gómez R., L. López G., M. Palma, I. Trejo V., A. Peralta, J. Prado M., A. Rodríguez A., R. Mayorga S. y F. González M. 2000. La condición actual de los recursos forestales en México: Resultados del Inventario Forestal Nacional 2000. Investigaciones Geográficas. Instituto de Geografía. Universidad Nacional Autónoma de México. 43 p.

Portilla O., E.; G. Silva L. y A.D. Cortés. 1998. Uso tradicional de las plantas en el humedal de Alvarado. In: G. Silva L.; G. Vargas M. y J. Velasco T., eds. De Padre Río y Madre Mar. Reflejos de la Cuenca Baja del Papaloapan, Veracruz. Tomo II. Gobierno del Estado de VeracruzLlave. p:291-314.
Rojas G., J.L.; A. Yáñez A.; J. W. Day y F. R. Vera H. 1992. Estuarine Primary Producers: Laguna de Terminos, a Study Case. In: U. Seeliger, ed. Coastal Plant Communities of Latin America. Academic Press, Inc. San Diego. p:141-153.

Rodríguez, S.H. y A.V. Botello, 1987. Contaminación enterobacteriana en la red de agua potable y en algunos sistemas acuáticos del sureste de México. Contaminación Ambiental $3(1): 37-53$.

Ruiz, C. A.; L.R. Chávez y M.J. Montoya. 1990. Detección prospectiva de contaminación fecal en la Laguna de Alvarado, Ver. In: X Coloquio de Investigación ENEP - Iztacala. Universidad Nacional Autónoma de México. p: 90.

SAS Institute, Inc. 1999. Statistical Anaysis System Institute Inc. Cary, NC.

Secretaría de Agricultura y Recursos Hidráulicos (SARH). 1970. Inventario Nacional de Gran Visión. Secretaria de Agricultura y Recursos Hidráulicos. Subsecretaria Forestal. SARH. México. 126 p.

Secretaría de Agricultura y Recursos Hidráulicos (SARH). 1991. Inventario Nacional de Gran Visión. Secretaria de Agricultura y Recursos Hidráulicos. Subsecretaria Forestal. SARH. México. 158 p.

Secretaría Estatal de Desarrollo Agropecuario (SEDAP). 1997. Plan estratégico para el desarrollo de la acuicultura en el Estado de Veracruz. Veracruz, México. Anexos. Tomo I: Diagnóstico. p 37.

Secretaria de Desarrollo Urbano y Ecología (SEDUE). 1989. Diario Oficial de la Federación. 2 de diciembre de 1989. 
Silva, J. A. y A.V. Botello. 1996. Evaluación del impacto ambiental de la Central Nucleoeléctrica de Laguna Verde. In: A.V. Botello; J.L. Rojas G.; J. Benítez y D. Zárate L., eds. Golfo de México, Contaminación e Impacto Ambiental: Diagnóstico y Tendencias. EPOMEX Serie Científica 5. Universidad Autónoma de Campeche. México. p:555-570.

Soberón C., G. y A. Yáñez A. 1985. Control ecológico de los peces demersales; variabilidad ambiental de la zona costera y su influencia en la producción natural de los recursos pesqueros. In: A. Yáñez A., ed. Recursos Pesqueros Potenciales de México: La Pesca Acompañante del Camarón. Programa Universitario de Alimentos. Instituto de Ciencias del Mar y Limnología. UNAM. p:399-486.

Soberón C., G.; A. Yáñez A. y J.W. Day Jr. 1986. Modelos ecológicos para análisis del sistema y manejo de los recursos pesqueros en el sur del Golfo de México. In: Ecología y Conservación del Delta de los Ríos Usumacinta y Grijalva. INIREBDivisión Regional Tabasco y Gobierno del Estado de Tabasco. p:423-458.

Thom, B.G. 1982. Mangrove ecology - a geomorphological perspective; In: B.F. Clough, ed. Mangrove Ecosystems in Australia. Canberra Australian National University Press. Canberra. 3-17.

Toledo, A. 1988. Energía, ambiente y desarrollo. Serie Medio Ambiente en Coatzacoalcos. Vol. 15. Centro de Ecodesarrollo. $382 \mathrm{p}$.

Toledo, A.; A.V. Botello; M. Herzig; M. Páez; L. Bozada; F. Contreras; M. Cházaro y A. Báez. 1989. La contaminación en la región del Río Coatzacoalcos. Ciencia y Desarrollo 15(86):27-46.
Turner, R.E. 1977. Intertidal vegetation and commercial yields of Penaeid shrimp. Trans. Amer. Fish. Soc. 106(5):411-416.

Twilley, R.R., 1988. Coupling of mangroves to the productivity of estuarine and coastal waters. In: B.O. Jansson, ed. Coastal Offshore Ecosystem Interactions. SpringerVerlag, Alemania. p:155-180.

Twilley, R. R. 1989. Impacts of Shrimp Mariculture Practices on the Ecology of Coastal Ecosystems in Ecuador. In: S. Olsen y L. Arriaga, eds. Establishing a sustainable shrimp mariculture industry in Ecuador. The University Rhode Island. Coastal Resources Center. p: 91-120.

Twilley, R., 1995. Properties of mangrove ecosystems in relation to the energy signature of coastal environments. In: C.A.S. May, ed. Maximum Power. University Press of Colorado. Niwot. p:43-62.

Twilley, R.R. y J.W. Day, 1999. The productivity and nutrient cycling of mangrove ecosystem. In: A. Yáñez A. y A.L. Lara D., eds. Ecosistemas de Manglar en América Tropical, Instituto de Ecología A.C. México. UICN/ HORMA, Costa Rica. NOAA/NMFS Silver Spring MD. EUA. p:127-152.

Twilley, R.R.; M. Montaño; J.M. Valdivieso y A. Bodero, 1999. The environmental quality of coastal ecosystem in Ecuador: Implications for the development of integrated mangrove and shrimp ponds management. In: A. Yáñez A. y A.L. Lara D., eds. Ecosistemas de Manglar en América Tropical. Instituto de Ecología A.C. México. UICN/HORMA, Costa Rica. NOAA/NMFS Silver Spring, MD. EUA. p:199-230. 
UNESCO. 1976. Guide to operational procedures for the lagoons. Project on Marine Pollution (Petroleum) Monitoring Manual and Guides 7. $134 \mathrm{p}$.

Vázquez T., G.; H. Barney y L. Torres. 1998. Humedal de Alvarado: aspectos socioeconómicos. In: M. Vázquez T., comp. Biodiversidad y problemática en el humedal de Alvarado, Veracruz, México. Universidad Veracruzana. p:49-124.

Vera H.; F.R., J.L. Rojas G.; C. Fuentes Y.; L.A. Ayala P.; H. Alvarez G. y C. Coronado M. 1988. Descripción ecológica del sistema fluvio-lagunardeltáico del Río Palizada. In: A. Yáñez A. y J.W Day, eds. Ecología de los Ecosistemas Costeros del Sur del Golfo de México: La Región de la Laguna de Términos. Instituto de Ciencias del Mar y Limnología UNAM, Coastal Ecology Institute LSU. Editorial Universitaria. México D.F. p:51-88.

Villanueva, S. y F. Páez O. 1996. Niveles de metales en el Golfo de México: agua, sedimentos y organismos. In: A.V. Botello; J.L. Rojas G.; J. Benítez y D. Zárate L., eds. Golfo de México, Contaminación e Impacto Ambiental: Diagnóstico y Tendencias. EPOMEX Serie Científica 5 . Universidad Autónoma de Campeche. México. p:309-347.

Viveros D., A. y L. Albert. 1996. Estudio Caso: Plaguicidas organoclorados en sedimento y organismos del Río Blanco, Veracruz. In: A.V. Botello; J.L. Rojas G.; J. Benítez y D. Zárate L., eds. Golfo de México, Contaminación e Impacto Ambiental: Diagnóstico y Tendencias. EPOMEX Serie Científica 5 . Universidad Autónoma de Campeche. México. p:169-176.
Walsh, G.E. 1974. Mangroves: a review. In: R.J. Reimold y W.H. Queen, eds. Ecology of Halophytes. Academic Press, Inc. 605 p.

Wong, I. y G. Barrera. 1996. Niveles de contaminación microbiológica en el Golfo de México. In: A.V. Botello; J.L. Rojas G.; J. Benítez y D. Zárate L., eds. Golfo de México, Contaminación e Impacto Ambiental: Diagnóstico y Tendencias. EPOMEX Serie Científica 5. Universidad Autónoma de Campeche México. p:383-397.

Yáñez A., A. 1999. Terms of reference towards coastal management and sustainable development in Latin America: introduction to special issues on progress and experiences. Ocean and Coastal Management 42(2-4):77-104.

Yáñez A., A. y J. Benítez T. 1991. Expansión urbana y ecología litoral en Isla del Carmen, Campeche, México. Jaina. 3 p.

Yáñez A., A. y A.L. Lara D., eds. Ecosistemas de Manglar en América Tropical. Instituto de Ecología A.C. México. UICN/HORMA, Costa Rica, NOAA/ NMFS Silver Spring, MD, EUA. $380 \mathrm{p}$.

Yáñez A., A.; R.R. Twilley y A.L. Lara D., 1998. Los ecosistemas de manglar frente al cambio climático global. Madera y Bosques 4(2):3-19.

Yáñez A., A.; D. Flores H.; P. Sánchez G.; A.L. Lara D.; J.L. Rojas G.; J. Ramos M.; F. Arreguín S. y J.A. Sánchez. 1994. Ecología de los recursos pesqueros en el sur del Golfo de México. In: A. Yáñez A., ed. Recursos Faunísticos del Litoral de la Península de Yucatán. Universidad Autónoma de Campeche EPOMEX Serie Científica, 2. p:111-132. 
Yáñez A., A.; A.L. Lara D.; J.L. Rojas G.; G.J. Villalobos; D. Zárate L. y P. Sánchez G. 1999. Integrated coastal zone management plan for Terminos Lagoon, Campeche, Mexico. In: H. Kumpf, K. Steidinger y K. Sherman, eds. The Gulf of Mexico Large Marine Ecosystem. Assessment, Sustainability, and Management. Blackwell Science Inc., Massachusetts. p:565-592.॰

1 Departamento. de Ecología Vegetal. Instituto de Ecología A. C. Apdo Postal 63. Xalapa 91000 Veracruz. México. c.e.: patricmo@ecologia.edu.mx.

2 Dirección de Planeación Ambiental. Subsecretaría de Medio Ambiente. Secretaría de Desarrollo Regional. Gobierno del Estado de Veracruz. Fco. I. Madero s/n, Esq. Juárez. Zona Centro. Xalapa 91000 Veracruz. c.e.: zarate.@sdmaver.gob.mx.

3 Instituto de Geografía. Universidad Nacional Autónoma de México. Geografía Física. Circuito exterior s/n. Ciudad Universitaria. 04510 México, D.F. c.e.: maop@igiris.igeograf.unam.mx.

4 Secretaría de Medio Ambiente y Recursos Naturales. Delegación Veracruz. Av. Murillo Vidal Núm. 250, Col. Cuauhtémoc. Xalapa 91069 Veracruz. c.e.: teresav9@gmx.net.

Manuscrito recibido el 6 de Diciembre de 2001.

Aceptado el 4 de Abril de 2002.

Este documento se debe citar como:

Moreno C., P.; J.L. Rojas G.; D. Zárate L.; M.A. Ortiz P.; A.L. Lara D. y T. Saavedra V. 2002. Diagnóstico de los manglares de Veracruz: distribución, vínculo con los recursos pesqueros y su problemática. Madera y Bosques Número especial:61-88. 